\title{
"WHO STILL WATCHES THE OLYMPICS ANYWAY?" AN EXPLORATORY STUDY OF GENERATION Z AND THEIR DIGITAL OLYMPIC BRAND EXPERIENCE.
}

\author{
by \\ Maha Waseem \\ A thesis \\ presented to Ryerson University \\ in partial fulfilment of the \\ requirements for the degree of \\ Master of Science in Management \\ in the program of \\ Master of Science in Management
}

BA in Advertising PR and Media, Middlesex University, 2018

Toronto, Ontario, Canada, 2020

(C) Maha Waseem, 2020 


\section{AUTHOR'S DECLARATION}

I hereby declare that I am the sole author of this thesis. This is a true copy of the thesis, including any required final revisions, as accepted by my examiners.

I authorize Ryerson University to lend this thesis to other institutions or individuals of the purpose of scholarly research.

I further authorize Ryerson University to reproduce this thesis by photocopying or by other means, in total or in part, at the request of other institutions or individuals for the purpose of scholarly research.

I understand that my thesis may be made electronically available to the public. 
"WHO STILL WATCHES THE OLYMPICS ANYWAY?"

\title{
AN EXPLORATORY STUDY OF GENERATION Z AND THEIR DIGITAL OLYMPIC BRAND EXPERIENCE
}

Maha Waseem

Master of Science in Management, 2020

Master of Science in Management, Ryerson University

\begin{abstract}
Despite being the most watched sporting event in the world, the Olympic Games have struggled to maintain relevancy amongst younger audiences (Pentony, 2016). The purpose of this study was to explore Generation Z's Olympic brand experience. Using the Theory of Planned Behaviour (TPB) as a theoretical lens, this research employed a focus group methodology to uncover what the Olympic brand means to a sample Generation Z population and gain valuable insight relative to the influence of TPB variables on this generation's brand perception, brand awareness, and brand engagement with the Olympics. Notably, 59\% of participants were unaware that 2020 was a planned Olympic year. Findings suggest this age cohort has fond memories of the Olympic brand from their youth, but have largely disengaged with the brand as young adults. This sample reported largely negative brand associations, a declining interest in long-form sport, and a disconnect with current digital branding strategies. Keywords: Olympic Games, Media Consumption, Generation Z, Focus Groups
\end{abstract}




\section{Acknowledgements}

Graduate school has been a fruitful yet challenging journey; from experiencing the joys of moving to a new city to watching the world navigate its way through a global pandemic. Without the support of many, I would not have been writing this paragraph today. First and foremost, I would like to thank my research supervisor, Dr. Katie Lebel, for supporting me throughout my research process. Her insight, guidance and wisdom have been invaluable during my time at Ryerson. I would like to extend this gratitude to my parents without their encouragement and support, this would not have been possible. Finally, I would like to thank Sam Sibalis for his love, quirky sense of humour and emotional support especially during trying times. You are nothing short of amazing. 


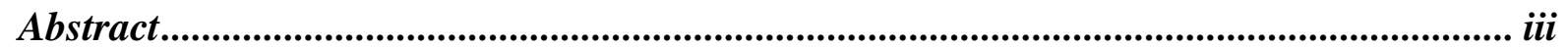

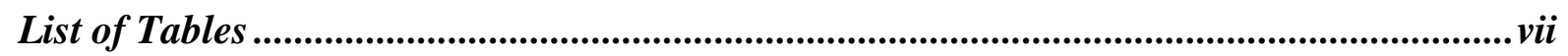

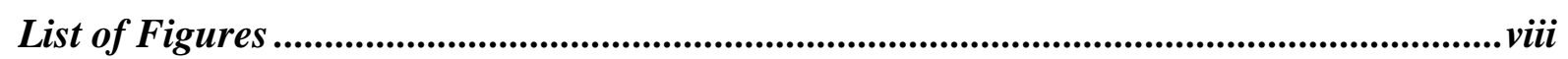

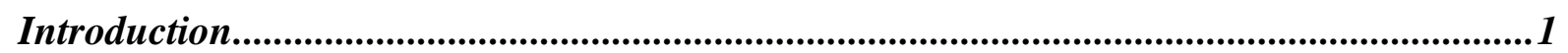

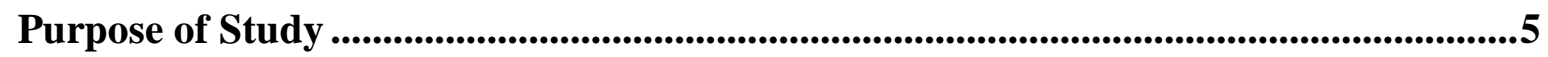

Significance of Study..........................................................................................................................5

Assumptions........................................................................................................................................6

Research Objectives.................................................................................................................................66

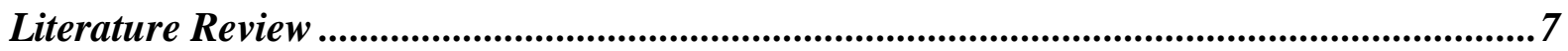

A History of the Olympic Movement ............................................................................

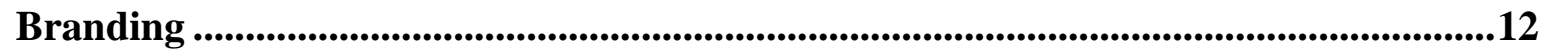

Digital Brand Expectations ...........................................................................................16

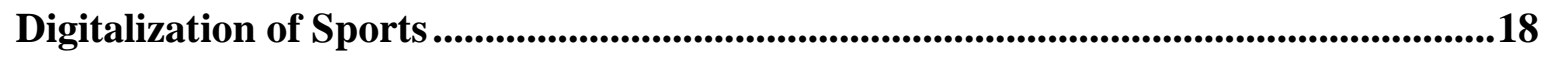

Second Screen Behavior ............................................................................................19

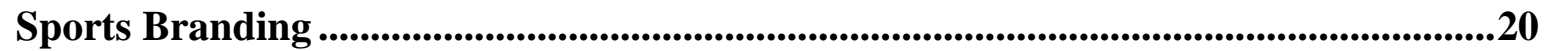

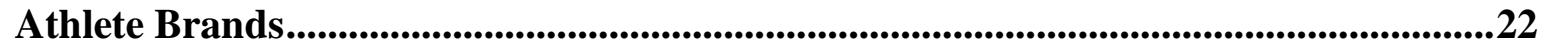

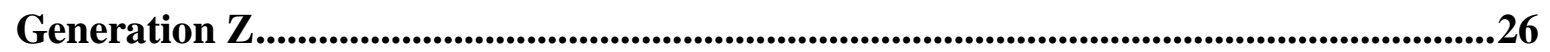

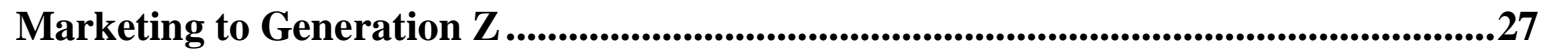

Generation $\mathbf{Z}$ and Sports Consumption .....................................................................28

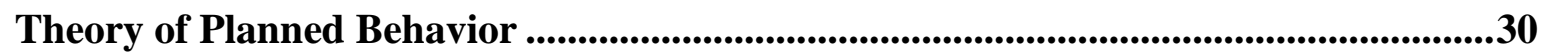

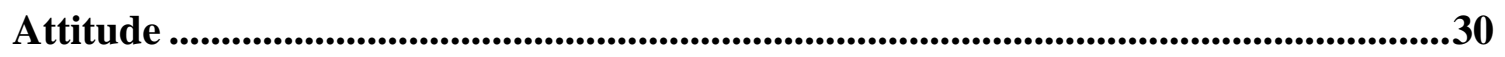

Subjective norms .............................................................................................................................30

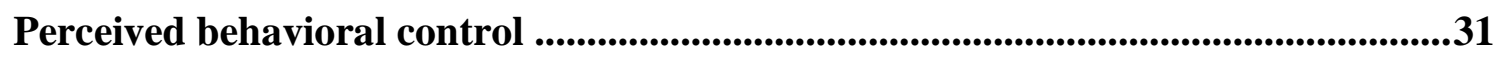

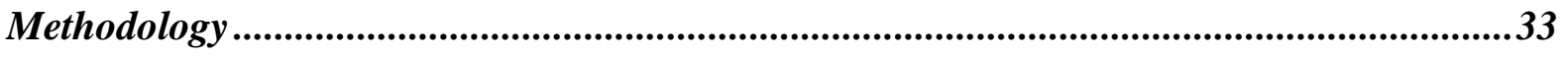

Procedure

Participants........................................................................................................................34

Data Analysis........................................................................................................................................35

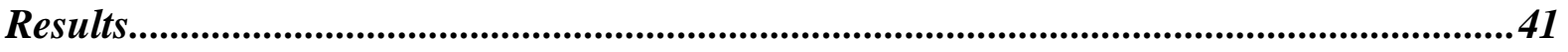

Generation Z Sport Consumer Profile.............................................................................41

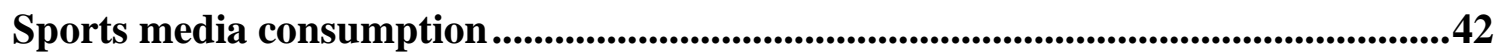

Gen Z Awareness of the Olympic Brand .............................................................................42

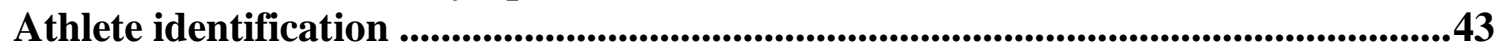

Frequency of events ............................................................................................................................44

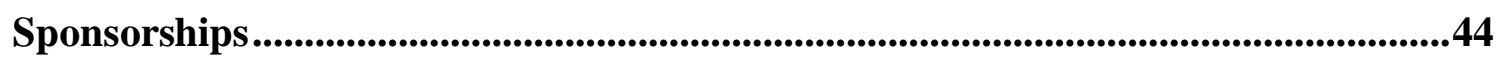

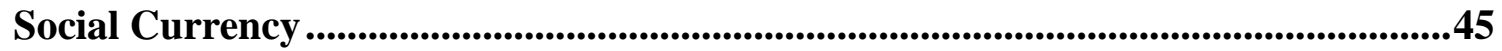




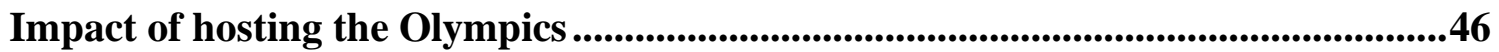

Gen Z Perceptions of the Olympic Brand......................................................................46

Corruption/Social Responsibility .........................................................................................47

Sports Achievement. ..................................................................................................48

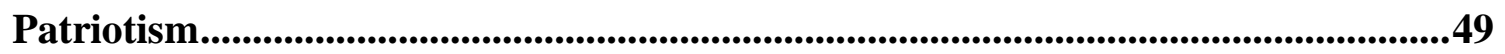

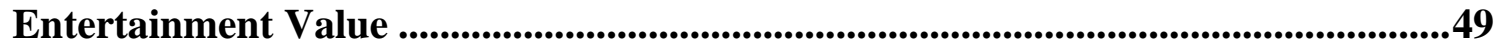

Generation Z Olympic Brand Engagement ...................................................................51

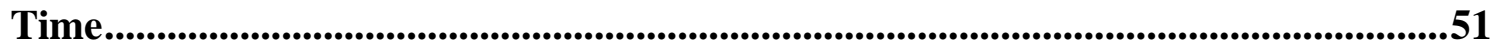

Storytelling..................................................................................................................................52

Unity ...............................................................................................................................................5

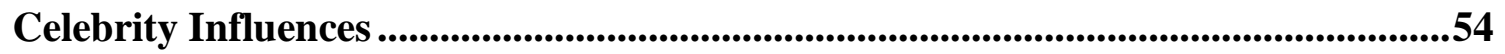

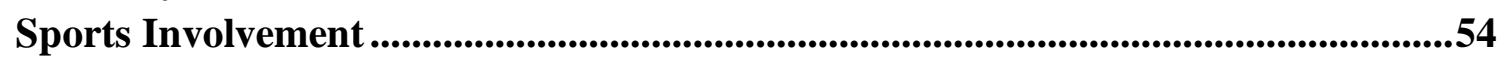

Sociability ...............................................................................................................................56

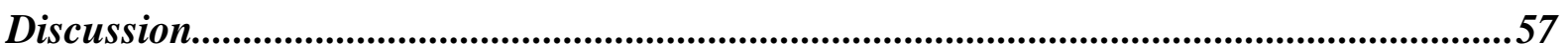

Gen Z Perceptions of the Olympic Brand.............................................................58

Generation Z Awareness of the Olympics ....................................................................................58

The Impact of Echo-Chambers..........................................................................59

Generation Z Sport Involvement .....................................................................................................660

Media Consumption......................................................................................................................661

The Role of Sponsorship..................................................................................................................63

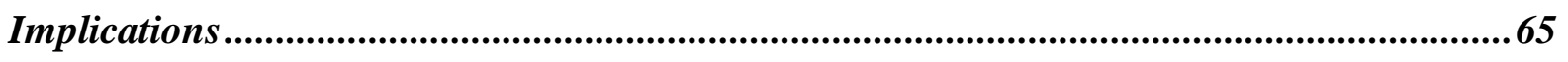

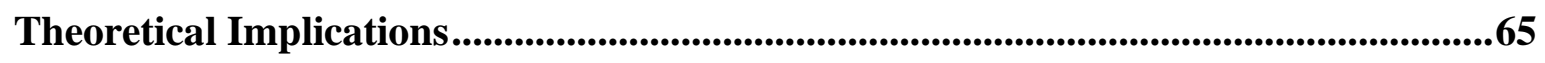

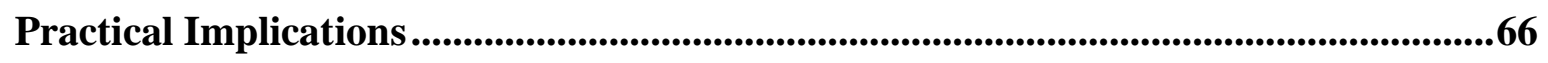

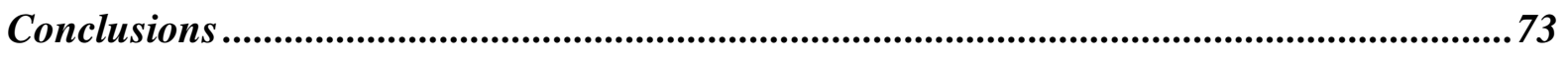

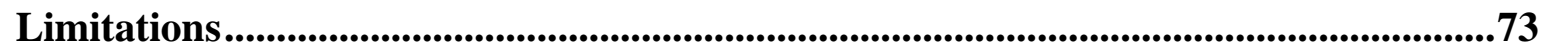

Recommendations for Future Research ....................................................................74

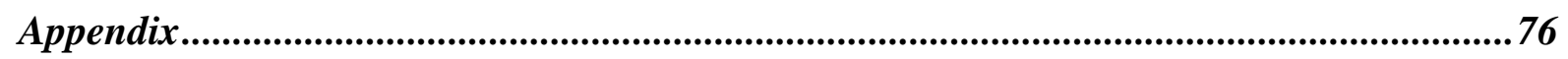

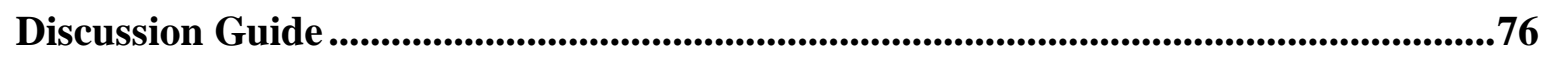

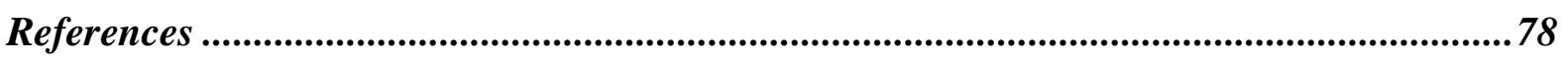




\section{List of Tables}

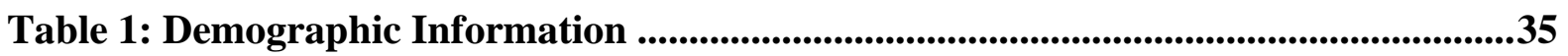

Table 2: Identifying a thematic framework....................................................................36

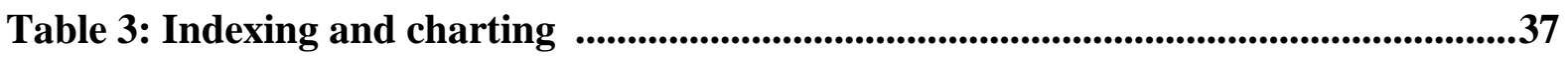

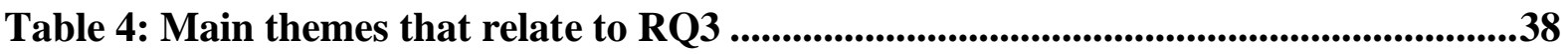




\section{List of Figures}

Figure One: Participant Classification 


\section{Introduction}

The Olympic brand is one of the most established brands in the world (Casella, 2017). Despite efforts to digitize the Olympic experience and maintain relevance with next generation audiences, the Olympic Games have recently struggled to attract younger audiences (Pentony, 2016). Research suggests the current median age of an Olympic viewer is 53 years old (Guzior, 2018). This poses a unique challenge for the IOC and Olympic stakeholders given that youth engagement with the Olympic Games affects their long-term viability (Kohe, 2015). Interestingly, both academic research and industry reports found the Olympic brand garnered largely positive brand sentiment in research conducted in 2008 and 2012 (Seguin et al., 2008; IOC, 2012). However, despite investments in streaming technologies to improve accessibility and steady increases in domestic rights fees, the 2018 Pyongchang Olympics became the least watched Games in Olympic history (Molla, 2018). Further, negative press surrounding the Olympic brand has increased in recent years (Faull, 2016; Grohmann \& Baker, 2018) and vast changes in consumer behaviour and media consumption strategies have seemingly compounded challenges (Lobaugh et al., 2019).

Accordingly, this research sought to investigate the relationship between Generation Z and their Olympic brand experience. The broad objectives of this study aimed to explore this cohorts' awareness of the Olympic brand, as well as their brand perceptions, and brand engagement. Azjen's (1991) theory of planned behaviour (TPB) was used as a theoretical framework to illuminate how changes in media consumption habits and evolving consumer expectations have impacted the relevancy of the Olympic brand among this generation in the modern sports landscape. Within the context of business management, past research has explored the effects of sponsorships, brand consistency, and ambush marketing in relation to the Olympic brand. However, the growing power of Generation Z presents a new important 
area for research. This investigation of Generation Z's perception of the Olympic brand exists as the first known research to explore this intersection through a business lens.

The Olympic Movement. Since 1896, The Olympic Games have symbolized sporting excellence and national pride for various communities and cultures around the globe (Lee, 2005). The Games have economic, social, and political significance that is unlike any other sporting event; they create artistic value through the use of historic narratives and provide host nations with the opportunity to make a special appearance on the global stage (Scandizzo and Pierlioni, 2017). Today's Olympic Games have evolved into a media event that is extensively televised for global audiences to consume (Varley, 2016). This was made possible when private companies and TV broadcasters entered the media landscape and changed the way sports content was distributed and consumed (Shoval, 2002). Although the 1964 Tokyo Olympics were the first to be internationally televised, it wasn't until 1984, when the American Broadcasting Company (ABC) won exclusive rights to broadcast the Summer Olympic Games in Los Angeles for \$225 million USD that the value of broadcasting rights became apparent (Lindsey, 1979). This continues to be an important source of revenue for the International Olympic Committee (IOC) and many other mega-events that operate in similar ways.

In the 2000's, technology became more democratized and accessible. Mobile phones gained immense popularity, cellular data became cheaper and social media networks like Facebook started making a name for themselves (Westcott et al., 2018). As a result, the way content was consumed began shifting again. Video-streaming on platforms such as YouTube gained traction and Instagram became a major social media competitor. As more companies entered and caught up with this shift, the media environment became highly fragmented (Nielsen, 2018). A more recent and on-going trend seems to favour Over the Top (OTT) media services such as DAZN and ESPN+ (Westcott et al., 2018). Similar to Netflix, these services are gaining popularity due to the viewing convenience that they offer (Neilson, 2018). Sports 
organizations are increasingly acquainting themselves with digital media and new technologies to remain relevant and profitable in a rapidly evolving sports industry. The IOC has made efforts to adapt to our increasingly mediated environment by emphasizing digital live coverage, launching the Olympic Channel, and maintaining a social media presence. There is a noted recognition of the importance of fostering a relationship with next generation Olympic fans among Olympic stakeholders. This research serves as a step forward to better understanding the Generation Z Olympic brand experience (Kohe, 2015).

Generation Z. Currently, the most desirable target audience for many marketers is Generation Z, or individuals born between the years 1995-2012 (Littleton, 2018). This age cohort has distinct consumption habits, priorities, and beliefs (Barret, 2018). They're known to be creative, innovative, demanding, and tech-savvy (Priporas, 2017). Growing up with cellular data and mobile phones has made them one of the most globally connected generations (O’Brien, 2019). Research conducted by Forbes (2018) has showed that in 2020, Generation Z will account for $40 \%$ of all consumers and will hold $\$ 143$ billion dollars in spending power. They currently consist of $32 \%$ of the global population with 2.47 billion members and are expected to become the largest consumer group in the United States by 2026 (Spitznagel, 2020). This makes them a crucial demographic to cater to. From a marketing perspective, it is critical to monitor their consumer behaviour and corresponding preferences, particularly since sports in general seem to be of less importance to this age segment, which could largely affect their corresponding levels of engagement with the Olympic brand (Petony, 2016).

Additionally, corporate branding plays a large role in creating business value. Sporting brands in specific have made billions of dollars in revenue by effectively marketing themselves (Razvan and Catalin, 2018). Sports sponsorships, athlete endorsements and sports merchandise are some popular methods of branding used by sports organizations (Lee and Choo, 2009; Arai et al., 2014). Digital marketing has become an important feature to sports marketers since a 
large number of consumers interact with brands online (Pfhal et al., 2012). Utilizing an effective digital strategy is known to be a powerful way of engaging with new audiences and retaining existing ones as well (Schmid et al., 2016). Research indicates that Generation Z watches over 23 hours of video content per week (Eaton and Poulson, 2019). Creating highquality and shareable video content has become a potent way of reaching the youth online (Eaton and Poulson, 2019). As a result, Olympic sponsors have invested over \$5 billion USD in media activities and online sponsorship activations (Santomier et al., 2016). The London 2012 Games were particularly successful in reframing the ways in which the Olympic brand connected with digital audiences (Santomier et al., 2016). However, sports crowds can be extremely varied and complex in nature and the way media content is consumed is shifting. In order to consistently engage different consumer segments, it's recommended that their profiles, characteristics, needs and expectations be thoroughly understood and catered to (Schmid et al., 2016).

Theory of Planned Behaviour. This study uses Azjen's (1991) Theory of Planned Behaviour (TPB) and branding literature to explore the current relationship between Generation $\mathrm{Z}$ and their experience with the Olympic brand. TPB explains how behaviour can be predicted through the intention of performing a specific act. Azjen suggests that intentions are formed by three main variables: individual attitude, subjective norms, and perceived behavioural control (Azjen, 1991). These factors help evaluate the extent to which people will exert effort in exhibiting a particular behaviour (Cunningham and Kwon, 2003). From a branding perspective, the underlying factors that construct a consumer's intention can be used to evaluate how brand engagement can be optimized (Cunningham and Kwon, 2003). Hence, TPB will be used as a theoretical lens through which the attitudes, subjective norms and perceived behavioural controls of Generation $\mathrm{Z}$ will be examined in relation to the Olympic brand. 


\section{Purpose of Study}

The purpose of this study was to explore Generation Z's perception of the Olympic brand and to assess changing media consumption strategies within this demographic. Using the Theory of Planned Behaviour (TPB) as a theoretical lens, the goal of the research was to uncover what the Olympic brand means to the Generation $\mathrm{Z}$ age group and better understand which of the three TPB variables (attitudes, subjective norms and perceived behavioural control) influence this generation's brand perception, brand awareness, and brand engagement with the Olympics.

\section{Significance of Study}

Generation $\mathrm{Z}$ is seen to have more power and influence to change the way businesses function than any preceding generation (Priporas, 2017). They're expected to become the largest generation of consumers in 2020, representing approximately \$143 billion USD in direct spending (Fromm, 2018). This makes it imperative for brands to adapt to evolving production and consumption strategies or otherwise run the risk of becoming irrelevant in today's incredibly content-rich environment (Priporas, 2017). The Olympic movement has preserved its outstanding history and cultural significance over the course of several decades, however, it has recently struggled to maintain interest amongst next generation fans.

This study is worthy of attention because although there is plenty of research on Olympic branding, broadcasting, and framing (Billings, 2008; Marshal et al., 2010; Koenigstorfer \& Preuss, 2018; Brown et al., 2019), the relationship between Generation Z and their digital experience of the Olympic brand has yet to be explored. The study specifically focuses on digital experiences since Generation $\mathrm{Z}$ are tech natives that prefer to gather information and develop relationships with brands online (Duffet, 2017). Building a desirable online brand personality enables brands to foster cognitive connections with their consumers, which can lead to increased engagement and loyalty (Pfhal et al., 2012). It is critical that Olympic perception and consumption be explored since this provides the Olympic brand with 
insight on what Generation Z looks for in brands, sports content and how they wish to consume it. The results of this study provide sports marketers with practical implications that could help them enhance their brand's digital experience, thereby improving brand relevancy.

\section{Assumptions}

To successfully conduct this study, various assumptions are highlighted below by the researcher.

- Brands are perceived to have a favorable or an unfavorable online personality.

- Branded content is consumed on social media.

- Individuals participating are aware of the Olympic brand.

- Individuals participating are social media users.

\section{Research Objectives}

This study aimed to explore how changes in media consumption habits and evolving consumer expectations have impacted the relevancy of the Olympic brand in the modern sports landscape. Specifically, this research looked to explore a Generation Z population's views of the Olympic brand, and better understand their brand engagement with the Olympics. Three research questions were developed to help guide this research due to the exploratory nature of this study and the fact that it is the first known attempt to understand Generation $\mathrm{Z}$ in relation to the Olympic brand:

RQ1: What is Generation Z's awareness of the Olympic brand?

RQ2: What is Generation Z's perception of the Olympic brand?

RQ3: How does Generation $\mathrm{Z}$ engage with the Olympic brand? 


\section{Literature Review}

This chapter begins with an overview of the history of the Olympic movement and the Olympic business model. It then provides a review of the literature surrounding branding, Generation Z, and the theory of planned behavior.

\section{A History of the Olympic Movement}

The ancient Greek Olympic Games can be dated back to the early seventh century where events such as javelin contests and wrestling matches were held. Their well-established tradition and popularity initiated the idea of modernizing the Games (Peterson et al., 2015). The institution of the modern Olympics was established in 1896 by Baron Pierre de Coubertin, who believed that international sport could contribute to world peace and promote societal wellbeing (Malfas et al., 2004). Since then, the Games have brought countries together on a quadrennial basis and consistently reinforced the concept of world peace through sport proposed by Coubertin (Chapellet and Kubler-Mabbot, 2008). Today, the Olympics have become a multi-billion dollar global spectacle that features the world's top athletes competing in front of a global audience.

The Opening Ceremonies inaugurate each Olympic cycle with a colourful and rich display that highlights the grandiosity and global significance of the sixteen-day sporting event (Chapellet and Kubler-Mabbot, 2008). The Games have been described as a major media event that has the ability to create global connectivity and provide national unity (Nee, 2015). The Olympic Games have been unique in their ability to bring together thousands of international athletes, command exceptional media coverage, and subsequently garner rich corporate sponsorships (Maguire et al., 2008). The extensive global media coverage of the Games has to date been made possible by lucrative television broadcast deals. NBC famously spent $\$ 4.38$ billion USD in a multi-year contract for the official broadcast rights in the United States (Nee, 2015). More recently, social media content has become an increasingly important platform for 
Olympic content distribution. For example, NBC, the official U.S. broadcast partner, provided 6,755 hours of content during the 2016 Rio Games (Tang and Cooper, 2018). This included Facebook live interviews with athletes, slow motion videos of inspiring videos, daily live stories and more.

Collectively, the 2016 Summer Olympics in Rio hosted over 11,000 athletes from 206 nations competing in over 300 events for 28 sports, which illustrates both the complexity and popularity of the Olympics (Koenigstorfer \& Preuss, 2018). As a result, the Games have become a highly commercialized asset that has led to broadcasting networks bidding extremely large sums of money to the IOC for exclusive rights to air the sporting events in specific countries and regions.

Sport and business have had a close and mutually beneficial relationship for many decades. Today, sports marketing and branding play a crucial role in the success of sporting events, while sports in turn, provide access to a lucrative audience for brands and properties. (Maguire et al., 2008). Billings (2008) asserted that the evolution of the sport industry has become a central component of the global media entertainment industry. The introduction of telecommunication in the 1960 's allowed audiences to consume Olympic coverage live, which led to a surge in television ratings in the late seventies. Private media companies started competing for broadcasting rights of the Games because this provided them with the opportunity to reach a global market through a single event's platform.

Tapping into this source of revenue, the IOC initiated their own international marketing program called "The Olympic Program" (TOP) in 1985. This program is a worldwide sponsorship program that provides funding to all 199 National Olympic Committees (NOC's) and serves as a global promotional platform for the Olympic brand (Preuss, 2002). TOP gives all thirteen Olympic partners exclusive global marketing rights within their respective product or service category, in exchange for financial support and goods and services contribution 
(International Olympic Committee, 2019). Eighteen percent of the IOC's revenue is generated through TOP, which today includes global partners such as Coca Cola, Visa, Samsung and Procter \& Gamble (International Olympic Committee, 2019). The majority of Olympic revenue is produced from selling broadcasting rights, which account for $73 \%$ of the total revenue. Olympic broadcast partnerships from over 200 regions have enabled the Olympic movement to be financially viable for over three decades, with the aim of providing global coverage of the anticipated sporting event (International Olympic Committee, 2019).

Nickisch (2016) likened the business model of the Olympic movement to a franchise model. In this light, the IOC sells various rights to different stakeholders; the right to broadcast, host, advertise, and/or sponsor the Olympic Games. In order for this business model to be sustainable, there needs to be demand in all the mentioned areas. While there has to date been a competitive demand around broadcasting rights, the demand to host the Games and interest in being an official Olympic sponsor have waned in recent years. For example, residents of potential host nations have begun to doubt the benefits of hosting the Olympic Games, instead fearing the economic, social, and environmental strains that the event has recently brought upon previous host cities such as Rio and Beijing (Koenigstorfer \& Preuss, 2018). Additionally, the rising cost of Olympic sponsorship, cord cutting, and the strict promotional constraints enforced by the IOC have made sponsoring the event a challenge for many brands (Garcia, 2018). An exception to this has been an increased interest in Olympic sponsorship from EastAsian companies such as Ali Baba and Toyota (Garcia, 2018), which may illustrate an enhanced partnership interest in this specific marketplace.

By and large, the challenges facing the Olympic Movement in many ways culminate with the reportedly waning interest among next generation consumers. It is widely argued that a lack of interest among the youth demographic exists as one of the most pressing tests for the IOC. To this end, the Youth Olympic Games (YOG) were initiated in 2010 as a strategic 
initiative to reinforce the relevance of Olympic sport amongst youth (Peterson et al., 2015). The YOG is limited to participants aged between 15-18 and aims to bring together athletic youth from around the world to promote Olympic values (IOC, 2014). The ten-day event seeks to raise awareness on the importance of maintaining a healthy lifestyle, being an ethical athlete and to represent local communities on a global scale (Slater, 2009). Despite the YOG's positive attributes, there are growing concerns regarding the economic feasibility of the event (Peterson et al., 2015). Kreiger (2012) stated that most athletes that participate in the YOG do not consider it to be the main sporting event of the year. The research involved interviews with YOG athletes and found that participants barely prepared for the event since winning a medal at the YOG was merely a 'secondary goal' and did not have any direct impact on world rankings or personal funding (Kreiger, 2012). Event awareness was another critical issue associated to the growth and development of the YOG. A low level of public awareness was recorded amongst several target audiences, including parents, sports coaches, and the athletes themselves (Peterson et al., 2015). This could make it more difficult for the YOG to find cities that are interested in hosting the event (Peterson et al., 2014). Despite the YOGs effort in adding an exciting, new element to the Olympic movement, they have yet to demonstrate its success in harnessing youth interest towards Olympic sports.

\section{Olympic Nationalism and Framing}

The Olympic Games are viewed as one of the premier global sporting events in the world. The Games represent a harmonious unity between a multitude of nations (Lee and Maguire, 2009). However, while the Olympics have traditionally drawn significant audiences, for most fans, their experience with the Games is completely mediated. This sets up the media as a particularly influential entity as the ways in which media outlets cover the Olympics have the ability to shape the way global sport, culture, and talent is perceived by broader audiences (Angelini et al., 2017). Although the Olympics are seen to be an international sporting event, 
they carry a substantial amount of nationalistic expression due to their sheer scope and size. National flags, national anthems, and national teams are all ways in which patriotism is presented (Lee and Maguire, 2009). Nationalistic frames tend to provide more coverage and/or sensationalize certain aspects of the Olympic narrative to construct preferred meanings and discourses that are advantageous to a specific country. In choosing what to include or exclude from a story, the media produces different versions of a story, that contain different attributes and values (Zahrapoulous, 2007). Rowe (2003) claimed that the media actively frames global sporting events in a way that predominantly represents nationalistic values. This renders the discourse of building a 'global community' to a myth. Rowe asserted that media representations of global sport are in fact a rejection of a globalized world (Rowe, 2003). Maguire and Tuck (1998) hold a similar opinion on global sport and stated that "the close affiliation sport maintains with national cultures and identities also means that sport (which even in these global events is fundamentally 'national' in nature) undermines, and will continue to undermine, any regional political integration" (p. 111). By covering Olympic sports that are popular in a particular nation or in which the home country is most successful and concentrating on national team athletes, media networks take away from the grandiosity and global significance of the Games. Angelini et al., (2012) noted that Marit Bjørgen, a Norweigian female Olympian, won five medals at the Vancouver Games. However, she was listed at number 491 on NBC's most mentioned athlete list. Similarly, on The Canadian Broadcasting Corporation (CBC), Bjørgen was mentioned enough to place her as the 75 th most mentioned athlete, and even then, the coverage was not surrounding her notable accomplishments at the Games (Angelini et al., 2017). Similarly, Malia (2014) asserted that during the 2012 London Olympics, Olympisim was constantly overshadowed by elements of nationalism throughout British media by greatly emphasizing the Great Britain team. In essence, despite the global nature of the Olympics, an individual's home nation becomes the 'ingroup' while all other 
countries become the 'outgroup' (Angelini et al., 2017). This ideology takes away from the international and harmonious nature of the Games, arguably placing the grandiosity of the Olympics at risk.

\section{Branding}

The rapid proliferation of products and services has changed the way consumers make decisions; product and service differentiation has allowed companies to remain competitive in an evolving market (Aaker, 1998). This has also given rise to the many facets of branding that exist today. Clifton and Maughan (2000) have described a brand as a bundle of intangible and tangible features of a trademark, that generate revenue. A brand can be also be defined as an identifying 'mark' that creates a competitive advantage and fosters relationships with consumers on emotional and cognitive levels (Pfhal et al., 2012). Aaker (1997) highlighted that beyond simple differentiation strategies, brands have a distinct personality that is associated to human personality traits. This concept was introduced using a thoroughly tested and multidimensional measure (Davies et al., 2018). After 631 participants rated 37 brands using 114 personality traits, the five main characteristics that were said to be perceived by consumers included sincerity, ruggedness, excitement, competence and sophistication (Aaker, 1997). Although brand and human personality traits were compared in this study, it was mentioned that the personality formation process between humans and brands was different. Human personality traits are influenced by physical characteristics, behaviour, demographic characteristics or attitudes and beliefs (Aaker, 1997). Allen and Olson (1995) stated that brand personality traits are produced by an observer, to categorize the internal aspects of an organization. Kapferer (2008) asserted that by communicating with consumers, brands build a character that shows what kind of person the brand would be if it were human. All decisions made by brand managers are created to trigger cognitive responses in consumers that humanize

the brand (Allen and Olsen, 1995). Brand personality traits are formed by indirect or direct 
contact that is made with the brand. This could be through user imagery, logos, advertising styles, price, distribution channels or product related attributes (Deane, 2003).

In order to convey a brand's personality effectively, it is important to find sources that match the message being communicated. Maehle and Supphelen (2011) asserted that certain mediums are more appropriate for specific brand personality dimensions. For example, corporate sources are associated with competence and sincerity, whereas symbolic sources tend to be more related to ruggedness and sophistication (Maehle and Supphelen, 2011). Lee and Choo (2009) claimed that the personality traits associated with a brand go far beyond product related benefits and features. Demographic characteristics such as age, gender, social class and other non-functional symbolic qualities play a role in forming brand perceptions as well. This is because consumers see brands as a person who they would consider forming a relationship with. They can easily associate human characteristics to a brand due to the continuous efforts made by marketers in order to humanize it (Blackston, 2000). For example, research suggests that IBM's brand is widely considered to be old, whereas Apple is seen as youthful and relevant (Deane, 2003). Additionally, another factor that influences an individual's perception of a brand is their self-concept. Brand perception is largely dependent on how closely a brand represents a consumer's personal beliefs and personality (Malar, 2011). If a consumer sees their ideal characteristics reflected in a brand, they are a lot more likely to be attracted to it since the brand experience brings them closer to becoming their ideal self (Malar, 2011). Thus, brand attachment depends on the degree to which a consumer associates themselves to the brand and its respective values. Creating these brand personality associations encourage the formation of a preference for consumers who are presented with a plethora of options to choose from.

Although brands are defined based on concepts such as perceived quality, loyalty, awareness and association, all of these aspects can be grouped as factors that contribute to 
brand equity (Park et al., 2019). Brand equity refers to the added value that is associated to a brands name; it includes both customer-based and financial aspects of added value (Arai et al., 2014). Various industries use brand equity as a strategic tool that allows them to create a positive brand image, increase brand loyalty, brand awareness, and improved return on investment (Seguin et al., 2008). Customer based brand equity is of particular interest to this research since it specifically looks at brand knowledge and its effects on consumer response to marketing messages (Keller, 1993). This form of equity is achieved when a consumer holds strong, favourable and unique associations to a particular brand.

Marketing and advertising play a large role in affecting customer-based brand equity since these messages can improve an individuals' ability to recall, recognize and think more positively about a specific brand (Pfhal et al., 2012). More specifically, emotional marketing that includes powerful and relatable stories have a beneficial impact on brand equity (Nowak et al., 2006). Local brands are capable of improving customer-based brand equity more effectively since they can develop stronger relationships with their customers and build trust more easily (Schuilling and Kapferer, 2004). Managers of local brands have the ability to create advertising and marketing campaigns based upon local insights, which means that they can respond to their needs more efficiently (Schuilling and Kapferer, 2004). On the contrary, since international brands need to satisfy a wide range of consumers in diverse markets, their focus tends to be on finding a common denominator that works in all markets (Schuilling and Kapferer, 2004). Maguire et al. (2008) has stated that the greatest challenge for international brands is to stand for something that attracts a diverse set of people, while including elements that make the brand appealing for local markets. This contradiction reduces a global brands' ability to create intimate connections with their consumers. From a branding perspective, a big advantage that global brands can leverage is their association to prestige, status, superiority and high quality (Holt et al., 2003). In order to stay relevant and competitive, larger enterprises 
need to become more intelligent and use big data to better understand and anticipate the needs of consumers at a niche level (Gupta and Wright, 2019). In today's highly competitive market, brands need to evolve and adapt to changing consumer needs, which is more difficult for globally recognized and established brands to implement.

\section{Digital Branding}

Prior to the introduction of social networks and digital platforms, media communication channels such as radios, television and newspaper were utilized by brands to communicate with their consumers (Tiago and Verissimo, 2014). As technology has advanced, social networking platforms have led to a complete transformation of the communication process between brands and consumers. Traditional methods of marketing communications are in many ways no longer seen to be as effective since consumers are now looking for more personalized and interactive brand experiences (Shivinski and Dabrowski, 2014). Tang and Cooper (2018) claim that social engagement, affiliation, self-disclosure, information, and entertainment are some of the main consumer motivations for social media usage. Entertainment value in particular is seen as an important factor that contributes to social media usage. Contests, games, user generated content (UGC) and other interactive forms of entertainment generate interest and encourage consumer involvement (Killian and McManus; Brown et al., 2019). It took Instagram half the time to reach 150 million followers compared to Twitter, and two years less compared to Facebook (Gillett, 2014). This growth indicates the importance, preferability, and preference for entertaining platforms in the social media landscape (Killian and McManus, 2015). Brand managers have been urged to integrate multiple social media channels into their communication plans to help build relationships and engage with both current and potential customers (Tang and Cooper, 2018).

Although having a presence on all social media channels is encouraged, it is important for marketers to internalize that utilizing a limited number of social platforms that align with 
the company's strategic goals and their consumers' needs can be more beneficial than publishing content on all available channels (Killian and McManus, 2015). In order for social media messages to be engaging, they need to be tailored to the consumer's current needs, the strengths of the platform being used and the user's relationship with the firm, need to be taken into account as well (Killian and McManus, 2015). Since social networks are used to serve a distinct benefit, marketers can develop social media strategies by identifying the reasons behind their digital brand engagement. For example, YouTube videos are known to be consumed for their entertainment value, informative, and co-viewing nature (Haridakis and Hanson, 2009). These motivations can then be used to further improve their brands overall experience online (Killian and McManus, 2015). To excel in the digital space, it is important for brands to evaluate where their audience is, what they are talking about and how they can become a part of the conversation if they are to utilize the strength of social channels effectively (Radenovic, 2013).

\section{Digital Brand Expectations}

Consumer brand expectations have fundamentally shifted since the introduction of new media technologies. Some of the most popular trends in digital marketing include the production of UGC, the creation of live social media videos, and the personalization of content (Patel, 2018). The growth of online brand communities has encouraged the production and distribution of UGC (Gangadharbatla, 2008). Research suggests that users participate in content creation as a means to contribute to intrinsic satisfaction, self-promotion, and a desire to influence public perception (Shivinski and Dabrowski, 2014). Content generation can give rise to brand involvement since consumption related UGC usually contains branded products and services (Muntinga et al., 2012). UGC has significant effects on brand perception, since consumers often find the opinions of their peers more credible and trustworthy than corporate communications (Barreda and Bilghian, 2013). Corporate content is only seen to be effective 
in influencing brand awareness, it does not often impact consumer perception of the brand (Shivinski and Dabrowski, 2014).

The trust and credibility associated with the opinions of likeminded individuals has initiated the popularity of social media influencers. This means popular and relevant opinion leaders create content and generate positive word of mouth that influences consumer perception of certain brands and products (Barreda and Bilghian, 2013). Social media personalities have the ability to persuade and impact their followers using a brand story and vision in way that resonates with an audience (Forbes, 2016). This form of UGC has been found to be popular among audiences and successful for brand marketing initiatives (Forbes, 2016).

$\mathrm{Li}$ and Lin (2012) stated that building and maintaining relationships is one of the primary reasons for social media utilization. Using video content has been found to be a highly effective way of fostering relationships and interacting with different audiences (Dave, 2018). In 2017, the digital video marketing industry reached a $\$ 135$ billion valuation in the United States alone, due to the popularity of Facebook, Instagram and YouTube amongst millennials (Chaykowski, 2017). Live video streams create a two-way channel of communication between brands and consumers which increases engagement and creates a sense of authenticity (Agius, 2018).

Live content can be utilized in a variety of different ways which includes live Q\&A sessions, hosting interviews with experts, covering what happens behind the scenes and by product and service demonstrations (Agius, 2018). The authenticity and naturalness of the content makes the brand seem more 'human' and transparent since live videos are usually unscripted and produced in real-time (Dave 2018). Most social media platforms, including Facebook, Twitter, Instagram, and YouTube, have launched a live video feature that allows brands to engage with their consumers. 
Lastly, personalization of content refers to the process of gathering customer data and using it to cater to individual consumer needs more accurately (Kang et al., 2015). This can include personalized product offerings, emails, onsite content and shopping experiences (Bullock, 2018). Eighty-six percent of consumers stated that a personalized experience has a significant impact on their purchasing decisions (Bullock, 2018). By analyzing customer preferences, personalized content increases brand loyalty and customer retention, since needs are met more efficiently (Liang et al., 2012). Incorporating engaging elements to a brand's digital marketing strategy can drastically elevate the overall brand experience.

\section{Digitalization of Sports}

New media technologies have greatly impacted the way media content is created, marketed, delivered, and consumed, especially during sporting events. The increase in smartphone usage and cellular data has made the access to social networking platforms extremely simple and convenient for people across the world (Tang and Cooper, 2018). Sport fans have demonstrated great interest in following and interacting with their favorite teams, athletes, and events on social media (Pfanner, 2012). Smith and Smith (2012) noted that in addition to following teams and athletes, sports enthusiasts have created chatrooms, blogs and online communities to debate topics such as the play of the game, coaching tactics, and other relevant sport details. The co-constructive and interactive nature of these digital platforms and online communities has left linear and unilateral modes of communications from brands increasingly less attractive (Pfhal et al., 2012).

Traditional methods of sports consumption and social media have attracted different audience segments (Nee, 2015). Casual sports fans and younger audiences have been found to be more likely to engage with sports on social media since they provide short video highlights, textual updates, and entertaining media content like GIFS and memes, whereas more traditional consumers have been found to be more committed to watching sport events live on television 
(Tang and Cooper, 2018; Nee, 2015). Thus, it can be said that social media has acted as an alternative source for sports consumption, which has significantly impacted the overall sports experience (Nee, 2015). Sports organizations are encouraged to use their digital following to attract both traditional and nontraditional consumers by building online brand communities, promoting underrepresented athletes and sports, and creating engaging content to deepen brand attachents (Tang and Cooper, 2018).

\section{Second Screen Behavior}

With attention spans getting shorter and technology becoming more accessible, the concept of simultaneous media consumption known as 'second-screen behavior' has become a common activity, especially amongst younger audiences (Guo \& Chan-Olmsted, 2015). Today, people want to watch what they want, when they want, and how they want (Mangold and Faulds, 2009). Forty percent of young adults use their laptops or mobile devices while watching television (Christensen et al., 2015). Consumers now prefer to view additional information related to the event on their second device as opposed to seeing it on the TV screen (Pfeffel et al., 2016). Sixty-three percent of second-screen behavior in the United States consists of social media usage, followed by chatting with others, and reading emails (Flint, 2018). This proposes both challenges and oppurtunites for sports marketers. Sports brands are provided with the chance to connect with their audiences by creating a sense of community formed around the televised event or by delivering informal learning opportunities (Nee, 2015). However, they risk losing the attention of their audiences due to the vast amount of entertainment that is now available for immediate consumption (The Telegraph, 2018). While mobile devices are becoming increasingly popular in the overall content consumption trend, the sport industry has been unique in that to date, live televised broadcasts have continued to be able to command the attention of large audiences (Brown et al., 2019). 


\section{Sports Branding}

Sports branding is defined as "a name, design, symbol, or any combination that a sports organization uses to help differentiate its product from the competition" (Shank, 1999). Many aspects of the global sports landscape, such as tournaments, teams, governing bodies, and individual athletes are now driven by the forces of corporatization to differentiate their offerings from their competitors. This has diversified revenue streams and enhanced the overall fan experience (Andrews and Grainger, 2007). The nature of sporting events has changed from solely being for competitive purposes, to becoming an anticipated source of entertainment for many around the world. There is an increased focus on production, delivery and the creation of entertainment value by these sporting events to maximize profits for sports marketers (Andrews and Grainger, 2007). Increased competition has led to companies using multiple media channels and publicity methods in order to sell products, services, and ideas (McAllister and Turow, 2002). Sports sponsorship, a fundamental dimension of sports marketing, enables communication between a brand and its consumers, builds brand awareness in new markets, and enables the production of creative content (Santomier, 2008). Similarly, Lee and Choo (2009) stated that sponsorship activities can strengthen, build or change brand associations when consumers form a cognitive and emotional relationship between the sponsored event and sponsoring brand. The sponsoring brand's image and associated attributes can also be transferred to the sponsored event through various marketing activities (Lee and Choo, 2009). Although sponsorship related marketing and advertising have similar goals, sponsorships have greater potential to engage and influence consumers since they target specific passions such as sport, art, or charity (Meenaghan and O’Sullivan, 2001). Brands are connected with content that is of interest to their audiences and in this process, brands build equity, awareness, and capture markets that favor them (Cornwell, 2008). Potential markets that are targeted through 
sponsorships include current and prospective customers, fans, channel members, and specific communities (Cornwell, 2019).

Official sponsors are increasingly seen to be restrictive from a brand usage perspective, since many brands want to expand their marketing efforts to social and digital platforms, but are restricted in how they can do so (Fowler, 2015). In today's cluttered sponsorship landscape, it is pivotal for brands to focus on digital engagement outcomes such as building loyalty, creating connections, and conversation amongst online audiences (Donlan and Crowther, 2014). The proliferation of social media provides brands with the opportunity to not only facilitate brand to consumer interaction, but consumer to consumer interaction, which has a greater impact on brand awareness and equity (Chu and Kim, 2011). The current digitalized media landscape requires brands to become more media savvy to remain relevant in the market of GIFS, memes and emojis (Fowler, 2015). They have to be resilient and confident enough for users to interact with their brand online, irrespective of their intentions (Fowler, 2015). To increase engagement, the focus must shift from what brands receive as a result of sponsorship, to what brands offer their customers (Donlan and Crowther, 2014). A failure to do so could result in the brand becoming outdated and irrelevant to tech-savvy audiences and sponsors.

A concern for brands that form multiple partnerships is the direct relationship formed with another brand and the almost immediate image transferability that comes with it. Connecting your brand with another proposes a reputational risk for both the sponsored and sponsoring brand since the actions of one could devalue another (Donlan and Crowther, 2014). Audiences and activist groups have become extremely vigilant in boycotting and criticizing brands that maintain sponsorship relationships with entities that are seen to be unethical, unauthentic, or just 'bad actors' (Batty and Gee, 2019). Thus, it is critical for brands to carefully assess their current and potential partnerships to ensure that there is coherence in brand values and an overall alignment in strategic vision. As an example, a senior researcher at Statista stated 
that the Arsenal and Emirates sponsorship relationship was seen to be a great match strategic vision due to their aligning values, shared brand attributes and international orientation (Cornwell, 2019). Additionally, the partnership between the International Paralympic Committee (IPC) and Toyota and the concept of 'mobility for all' was seen to be a very authentic and internally aligned sponsorship deal between the two brands (Cornwell, 2019). Consumers respond more positively to sponsorships that are perceived to be more 'fitting' and natural (Speed and Thompson, 2000). Although most brands aim for partnerships that fit naturally, many audiences tend to miss the relevance if the connection is not promoted correctly (Deane, 2003).

\section{Athlete Brands}

In the current sports marketing environment, the need for professional athletes to promote themselves online is becoming increasingly important (Hodge and Walker, 2015). According to Arai et al. (2014), an athlete's personal brand involves the symbolic meaning and value attached to an athlete's face, name, lifestyle, and other relevant brand elements. Similar to a traditional brand, athlete brands have logos, fan bases, and certain attributes associated to them and they act as differentiators from other personalities (Hodge and Walker, 2015). While a conventional brand is defined by certain characteristics of the product or service, a personal brand is portrayed through the attributes of a specific person (Parmentier \& Fischer, 2012). This could include physical attractiveness, a marketable lifestyle, and for sports professionals, athletic performance (Hodge and Walker, 2015). The accessibility of social media has made selecting and publishing carefully chosen content extremely easy, which allows individuals to display a 'likeable' version of themselves online (Eagleman and Burch, 2015). These athletes inevitably become cultural symbols that have social meanings attached to them due to the exhibition of their personal style, lifestyle and personality on social media (Eagleman and Burch, 2015). Publishing personal content online has transformed the way athletes interact with 
fans. Sports professionals are also able to present themselves as more authentic and real which can build a stronger connection between the athlete and their audiences (Pegoraro and Jinnah, 2012).

Moreover, this allows the athlete's fanbase to transcend traditional sport enthusiasts. Individuals who find the athlete attractive, share the same interests, or just enjoy the lifestyle of the athlete, tend to follow them on social media platforms (Eagleman and Burch, 2015). The increased and varied fanbase improves brand equity of organizations that are linked to the athlete due to increased ticket sales, traditional media coverage, partnerships and memberships (Parmentier and Fischer, 2012). Since a sports team's performance is inconsistent and does not ensure a favorable outcome, sports marketers often rely on the brand equity of an individual athlete (Park et al., 2019). Athlete brand equity contributes to attendee satisfaction, adds entertainment value, positively affects behavioral intentions, and word of mouth marketing (Park et al., 2019). Similarly, Hodge and Walker (2015) stated that famous athletes can have a positive impact on consumer brand perception since a famous athlete increases the attractiveness of the team they are associated with. Branded athletes have previously been found to impact higher sales, attendance, and television ratings (Franck and Nüesch, 2012). On the contrary, an athlete's lifestyle choices can have negative impacts on their brand equity. Scandalous activities such as drug use, gambling, and extra marital affairs can have large reputational effects on the athlete and the associated team. Hence, it's critical for sports marketers to not only observe athletic performance, but lifestyle decisions and off-pitch habits as well (Park et al., 2019).

Many athletes have become actively involved in businesses and social initiatives to extend their influence beyond the sporting sphere (Arai et al., 2014). For example, Serena Williams activated a partnership with Bumble and Venus; Maria Sharapova founded a candy business called 'Sugarpova', and Michael Phelps began the Michael Phelps Foundation as a 
means to promote active lifestyles among children. These are all considered to be forms of celebrity co-branding since there is an apparent, public relationship between two brands (Seno and Lukas, 2007). The growing importance of sports 'celebrities' within the sports landscape is an important element of the commodification and corporatization of sport and how various stakeholders are looking to capitalize off of the immense popularity of this sector (Andrews and Grainger, 2007).

\section{The Olympic Brand}

The IOC's decision to commercialize the Olympics and create a marketing program substantially changed the way the organization operated. In 1997, the IOC published a research study which showed that the Olympic rings were the most recognized symbol among both noncommercial and commercial logos compared to other sports symbols that were tested (IOC, 1997). The same study showed that the Olympic rings were associated with success, international co-operation, a tradition of excellence, national pride, and peace. Encouraged by the positive response, the IOC decided to conduct an examination of the attributes and imagery of the Olympics. This global study was done with the purpose of developing and building the Olympic movement and its brand in the most strategic and marketable way possible (Maguire et al., 2008). Today, the Olympic brand is one of the most established in the world and holds strong emotional connections with people from diverse cultures and nations around the world (Kenyon et al., 2018). Each Summer and Winter Olympic event formulates its own brand, that is guided by the core values of the main Olympic brand alongside the identity of the host city (Kenyon et al., 2018). The five working principles of Olympisim are: collaboration, solidarity, autonomy, social responsibility and universality. In addition to that, the three fundamental Olympic values include friendship, excellence, and respect (IOC, 2019).

After defining and outlining Olympic ideals and brand attributes so clearly, it's pivotal for managers to commit to these values both internally and externally. Actions that confuse, 
dilute or betray these ideals would risk damaging the brand as a whole (Seguin et al., 2012). Publicized scandals associated with doping, corruption, and fixing events severely damage the Olympic brand and consequently decrease its value. An Olympic partner expressed that "failure to live up to the brand promise" was one of the most pressing challenges for the Olympic brand (Seguin et al., 2012). In terms of consistency and coherency of the brand, none of the working principles of Olympisim, nor their brand values, were present in the brand images recorded by researchers during the 2012 London Olympics (Kenyon et al., 2018).

In order to regulate organizational activity, the Olympic charter has drafted rules to prevent unauthorized advertisement and commercialization of the Games. Epstein (2017) has mentioned that Rule number 40 clearly states that "Except as permitted by the IOC Executive Board, no competitor, coach, trainer or official who participates in the Olympic Games may allow his person, name, picture or sports performances to be used for advertising purposes during the Olympic Games" (p. 352). This means that athletes cannot be endorsed by unofficial sponsors that wish to include them in their marketing campaigns. For the 2016 Rio Olympics, some changes were made to make Rule 40 more lenient. The revised rule now states that nonsponsors could feature Olympic athletes and conduct Olympic related marketing, provided marketing plans were submitted by January of the same year, and campaigns begun promptly in March (Rivers, 2016). Not many brands utilized this opportunity since most athletes had not qualified to participate in the 2016 Olympics by January, making it a risky endeavor since brands were unaware of who might be competing. Under Armour was one of the few brands that took advantage of the relaxed rule during the 2016 Rio Games (Rivers, 2016). Although this rule was made to prevent over-commercialization, it had larger implications on the digital engagement and overall image of the Olympic brand, especially amongs the youth demographic. In addition, the regulations surrounding Olympic advertising limit athletes and 
teams from creating or benefiting from Olympic exposure in the years that the Games are not being held (Eagleman and Burch, 2015).

\section{Generation Z}

Over the course of several decades, many social, political and economic events have taken place that have largely shaped the cultural practices and lifestyles of individuals living in that particular era (Scroth, 2019). Inevitably, these societal changes create generational differences and largely influence each age cohorts' expectations, values, experiences and beliefs (Williams and Page, 2011). The post millennial generation, known as Generation Z, were born between the years 1995 and 2012 (Bassiouni and Hackley, 2014; Gale, 2015; Priporas, 2017), and while they share commonalities with millennials, some attributes are very distinct to this influential demographic (Grow and Yang, 2018). This generation has never experienced the world without internet connectivity, which has made them extremely tech savvy and subsequently, weakened their attention spans (Beall, 2016). Technology plays a large role in their lives since it is commonly utilized for entertainment, education, exercise, relaxation, and transportation (Scroth, 2019). Although millennials were considered to be the first global generation due to rapid internet development, Generation $\mathrm{Z}$ is marked by their global interactions and thinking (Beall, 2016). They have a collaborative attitude and are motivated to take action and advocate for causes that have a tangible impact on systematic problems (Loveland, 2017). Social issues such as diversity and inclusion, global warming, and equality are not only more salient, but expected by this generation (Scroth, 2019). Authenticity and uniqueness are greatly valued by Generation Z; they have a good idea of what is real and what is not, thus, they are extremely unimpressed by inauthenticity (Williams and Page, 2011). Unlike older generations, Generation Z shuns conformity, tradition, and comparatively are the least patriotic (Grow and Yang, 2018). The need to belong and peer acceptance is important to this generation; their self-concept is easily influenced by the group to which they 'belong' 
(Williams and Page, 2011; Loveland, 2017). Understanding how this generation views and interacts with the world is crucial in developing a relationship with them, that may benefit many stakeholders in the near future.

\section{Marketing to Generation $\mathbf{Z}$}

To remain relevant in a dynamic global marketplace, businesses need to adapt to changing trends to meet consumer needs more effectively (Saxena, 2019). It is pivotal for brands to make an effort to understand and appreciate Generation $\mathrm{Z}$ since $40 \%$ of all consumers by 2020 are predicted to be from this generation (Forbes, 2018). Targeting Generation $\mathrm{Z}$ is seen to be a marketing challenge since they are highly demanding consumers (Saxena, 2019). They need to be told what they need before they can express it for themselves (Forbes, 2018). As opposed to being loyal to brands, this generation expects brands to be loyal to them (Beall, 2016). Elegant customer experiences, entertaining interactions and authenticity matters a lot more to them than brand loyalty (Forbes, 2019). Additionally, due to the advancements in technology, Generation $\mathrm{Z}$ has grown up in an environment that includes personalization in just about everything (O’Brien, 2019). Games, mobile apps, accessories, and home décor are all examples of the popularity of personalization (O'Brien, 2019). The tech-centric lifestyle of Generation $\mathrm{Z}$ has made them quick decision makers and heavy social media users. This means that selling an idea, product, or service needs to be done quickly if attention and interest are to be retained (Forbes, 2016). The increased use of digital mediums like smartphones, tablets and laptops has resulted in a constant switch between five to six screens a day (Duffet, 2017). This makes it crucial for modern brands to have mobile applications that provide interactive experiences on all platforms. All of these factors present a unique challenge for the marketers who are trying to impress this age group.

In terms of digital content, Generation $\mathrm{Z}$ prefers media in small bites. Video content, UGC and engaging stories that are focused, individualized, and direct are seen to be the most 
effective in enticing young consumers since it generates word of mouth (WOM) (Duffet, 2017; Forbes, 2018). Furthermore, highlighting company values and their societal contributions can resonate with this generation if done in an authentic and unique way (Forbes, 2018). Trusting consumers to interact with each other online and sharing content that they have created enables them to define their experience online, which can contribute to brand loyalty (Duffet, 2017). An important note to make is that although Generation $\mathrm{Z}$ relies on online sources of information, they also heavily rely on face-to-face interactions at spaces such as pop ups. This suggests that marketing strategies should try to include both elements (Duffet, 2017). When marketers start to leverage the different consumption habits and behaviors of different generations, it will become significantly easier to build relationships and trust with different age groups, specifically Generation Z (Williams and Page, 2011).

\section{Generation $\mathrm{Z}$ and Sports Consumption}

The youth market has always been an important part of the sports industry, and this continue to hold true. Generation $\mathrm{Z}$ loves and enjoys sports just as much, if not more than previous generations (Poe, 2019). However, the way sports content is consumed is changing at an unprecedented rate (Neilsen, 2018). Many media broadcasters have seen a decline in television ratings, especially amongst youth audience. One of the key challenges is that in today's landscape, Generation Z consumers either don't own a TV or don't have time to watch it (Withiam, 2017; Steigard, 2018). Only 45\% of Generation Z watch cable television, but around $71 \%$ have an online streaming service such as Netflix or Hulu (Claveria, 2019). This has disrupted the sports industry immensely since most sporting leagues and events generate revenue through TV ratings and subsequent televised advertisements (Withiam, 2017). Poe (2019) asserted that the challenge is not getting this age group to watch sports, rather it's about changing the format of live sports distribution in a way that fits the needs of young people and sports organizations. The widespread popularity of social media has largely influenced the way 
content is consumed, sports included. Younger demographis prefer catching up with sports news by watching highlights on social media platforms rather than traditional SportsCenter broadcasts to avoid advertisements (Carufel, 2018). These trends actively threaten the business model of many sports organizations given the difficulty of monetizing digital consumption habits (Poe, 2019). Some argue it is likely that sports marketers and media broadcasters will shift their focus to begin catering to consumers directly via a Direct to Consumer model (DTC) in order to remain financially viable and popular in the future (Guichard, 2016). Over the Top (OTT) sports services like DAZN and Stirr have already become immensely popular, but this new infrastructure is still in its development phase (Schomer, 2019).

Finally, the definition of sports amongst the Generation $\mathrm{Z}$ demographic seems to be different to how previous generations defined the term. Non-traditional sports such as video gaming, trick shots, and extreme running are becoming increasingly popular amongst Generation $\mathrm{Z}$ since they believe that it's more relevant to them (Carufel, 2018). In efforts to attract the youth, the IOC has begun to introduce sports like skateboarding, karate, and sport climbing to the Tokyo 2020 Olympic Games (Chang, 2016). More recently, eSports have also become immensely popular (Rapoza, 2019). Even though a general consensus has not been reached as to whether or not eSports can be classified as a "sport", the early financial success of this industry cannot be ignored by sports businesses (Rapoza, 2019). Moreover, brands like Mercedes have begun sponsoring eSports venues and events to reach the youth in a new and dynamic manner (Brautigam, 2018). If leagues and sporting events want to attract more youth to sport, it would appear they willneed to go beyond traditional sports like hockey and football (Bechtoldt, 2018). Creating a relationship with Generation $\mathrm{Z}$ consumers using non-traditional sports could allow brands to connect with Generation $\mathrm{Z}$ and potentially offer a greater return on their marketing investments as well. 


\section{Theory of Planned Behavior}

Developed as an extension of the theory of reasoned action (Azjen and Fishbein, 1980), Icek Azjen introduced the theory of planned behavior (TPB) in 1991 to better understand the social and cognitive functions that affect human behavior. Both theories explain how attitudes and subjective norms largely impact an individuals' intention to exhibit certain behaviors. However, Azjen (1991) identified a limitation within the theory of reasoned action — the lack of consideration surrounding a person's ability to exhibit a specific behavior. Hence, he introduced a third variable that took into account the perceived ease or difficulty in conducting a particular behavior and called it 'perceived behavioral control' (Azjen, 1991). The idea behind the TPB is that an individual's intention is an indication of the amount of effort they are willing to exert. It is the extent to which they will put in effort to engage in a given behavior (Azjen, 1991). Generally, intention is positively correlated to performing a specific behavior; the greater the intention, the greater the likelihood of performing the behavior (Kim and James, 2016). Azjen (1991) postulates that attitudes, subjective norms and perceived behavioral control can be used as determinants of intention.

Attitude. The attitude variable refers to the degree to which a person has a positive or negative outlook towards the activity under consideration. If the behavior of interest is seen to be favorable, the attitude towards it is likely to be positive (Cunningham and Kwon, 2003). Individual preferences are automatic mechanisms and are reflected through attitudes, thus it is fair to conclude that they impact behavioral tendencies (Cheng et al., 2012). In relation to this study, attitudes towards the Olympic brand and their consequent effect on brand engagement will be observed.

Subjective norms. These can be defined as the socially acceptable way of acting within group settings. The implicit social pressure effects the way people perceive certain behaviors (Kim and James, 2016). Hegner et al. (2017) suggested that subjective norms are comprised of 
two parts, beliefs of what societal expectations are and individually formed beliefs about a specific topic. Generation $\mathrm{Z}$ is largely influenced by their peers and are said to have a "thoughtful worldview" (Loveland, 2017), which is why this variable is of interest to the current research.

Perceived behavioral control. Cheng et al. (2012) explain the concept of perceived behavioral control as an individual's self-assessment of their capacities and limitations including how they would affect their ability to engage in specific behaviors. This can be based upon the result of past experiences or anticipated difficulties and impediments (Azjen, 1991). According to Sparks et al. (1997), both internal and external factors contribute to perceived behavioral control. Internal factors include personal deficiencies, emotions, skills and abilities. Whereas external factors consist of accessibility, income and opportunity. Individuals who think that they are deficient of the factors that are needed to perform the behavior of choice, are less likely to form strong intentions, regardless of whether or not their attitudes and subjective norms are favorable (Hegner et al., 2017). This variable is important to this study since the access or the awareness of access to Olympic content and broadcasts can affect the engagement levels with the brand. Additionally, conflicting time-zones, long broadcasting hours, busy schedules, and time availability can be considered potential impediments, and thus factors contributing to perceived control and overall engagement with the Olympic brand.

Many researchers have used TPB as a theoretical framework in their studies to assess human behavior and intentions in various contexts. Some examples include online shopping behavior (Goby 2006; Hsu et al. 2006), eating disorders and body satisfaction (Pickett et al. 2012), risky credit behavior of young adults (Xiao et al. 2011), and acceptance of information technology (Truong, 2009). Within a sports and branding context, Cunningham and Kwon (2003) used TPB to predict sports consumption behavior amongst hockey fans. The results indicated that the three variables of TPB accounted for $64 \%$ of the variance in behavioral 
intentions. Another study conducted by Sutton et al. (1997) showed that in order to foster positive attitudes towards a sports team, it was important for athletic departments to improve team accessibility for fan interaction and increase community involvement. Hegner et al. (2017) used TPB to assess the factors that contribute to brand love. Attitude was shown to have a significant impact on brand love, followed by subjective norms that served as a facilitator as opposed to a cause. These studies show that this theory can be applied in various contexts to predict behavior and intentions, which would be highly beneficial when it comes to assessing Generation Z's current and future relationship with the Olympic brand and subsequently informing brand strategy. 


\section{Methodology}

This study employed the use of focus groups as its methodology since its primary aim was to build a raw database of thoughts and opinions surrounding the Olympic brand. Kitzinger (1994) defined focus groups as group discussions that elicit views and experiences by exploring a chosen issue or topic. This method of qualitative research provides an in-depth understanding of different experiences and beliefs and helps gather collective views as well (Gill et al., 2008). It has been said that focus groups can be used as a standalone method when the main goal is to discover group norms, processes and underlying meaning (Gill et al., 2008). From a marketing perspective, focus groups can help organizations develop strategies for their product or service that are better suited for their target audience (Daymon and Holloway, 2002). In the context of this study, focus groups were used to explore Generation Z's awareness of the Olympic brand, their perception of the Olympic brand, and their brand engagement with the Olympics via conversation around their preferred media consumption strategies. The intent was to inform marketers in the development of new methods to reach and communicate with Generation $\mathrm{Z}$ more effectively.

\section{Procedure}

Data collection occurred in January 2020, a planned Summer Olympic year. A Generation $\mathrm{Z}$ population was recruited through a digital research participant sign-up system that is available to students at the Ted Rogers School of Management at Ryerson University. This system allowed the researcher to list multiple timeslots for the focus groups and allow students to choose a time that suited them best. Once a timeslot was selected, each participant was assigned a unique numeric ID through the system to ensure anonymity. All participants were required to be born between 1995 - 2012 to ensure they met the Generation $\mathrm{Z}$ age requirement and participants were given $2 \%$ bonus marks for their participation. These credits were assigned to them through their unique participant ID, for their chosen course. 
Each focus group was conducted in a qualitative research lab at Ryerson University. The students were welcomed, asked to read a consent form that was printed for them, and reminded that their participation in the research was completely voluntary. Their age was verbally confirmed to ensure that they were within the Generation $\mathrm{Z}$ age range and once everyone was ready, the focus group began. Participants were asked to answer questions relative to Olympic perceptions, Olympic awareness, and Olympic engagement, including over-arching themes of sports participation, sports fandom, and mediated Olympic consumption. Some examples of the questions include "What is the first thing that comes to your mind when you think of the Olympic Games", "When are the next Olympics", and "What are your preferred methods of viewing sports and why". These questions were developed based upon the research questions (RQ1, RQ2 and RQ3) and findings that were outlined in the literature review (see Appendix). Beyond this, a flexible approach was taken to ensure that the group directed the discussion as opposed to the moderator. To ensure validity, readability, and clarity, the questions were discussed with the student researchers' supervisor.

Each focus group session lasted for an average of sixty minutes and was audio and video recorded in its entirety. In qualitative research, data is collected until it reaches a point of saturation to avoid redundancy (Saunders et al., 2017). It became apparent that different sets of people had similar thoughts and experiences on the discussion topics after conducting four focus groups. Data collection was discontinued after this point.

\section{Participants}

Omona (2013) asserted that the most common method of sampling in qualitative research is purposive. This means that participants are chosen if they are considered to be informed on the subject matter (Omona, 2013). Hence, purposeful sampling was used to recruit 22 participants that were subsequently organized into four focus group sessions. Participants were recruited from Ryerson's business school research pool as this is what was accessible to 
the researcher. Following Omona's (2013) suggestion, recruiting students from a business school was deemed an appropriate choice given this population is presumably aware of basic principles of marketing and its processes and thus, able to provide an informed perspective on the matter. Additionally, this study heeded the advice from Gill et al. (2008) which stated that the ideal size of a focus group is six to eight participants. Amongst the participants $(n=22)$ that were successfully recruited, there were 12 males $(n=12)$ and 10 females $(n=10)$ with a median age of 20.5. Some participants considered themselves to be athletic, some had engaged with sports in the past, others would engage with sports depending on the context or were uninterested in sports as whole. This enabled the researcher to gather insights from varied perspectives.

\section{Table 1.}

Demographic Information

\begin{tabular}{ccc} 
Category & $\mathbf{N}$ & $\mathbf{\%}$ \\
\hline Gender & & \\
Male & 12 & $54.5 \%$ \\
Female & 10 & $45.5 \%$ \\
& & \\
Age & & \\
18 & 3 & $13.6 \%$ \\
19 & 5 & $22.7 \%$ \\
20 & 5 & $22.7 \%$ \\
21 & 1 & $4.55 \%$ \\
22 & 4 & $18.2 \%$ \\
23 & 2 & $9.1 \%$ \\
24 & 1 & $4.55 \%$
\end{tabular}

\section{Data Analysis}

All focus group discussions were transcribed verbatim and then uploaded to the NVivo 12 qualitative data analysis computer software. The data were then analysed to identify notable patterns. Specific codes (or nodes) were created based on the data set, to organize and analyse the data. Kreuger's (1998) framework analysis was used to create clear steps to manage the 
large quantity of qualitative data. Ritchie and Spencer (1994) describe these steps as an analytical process that consists of distinct, yet highly interconnected stages. The five key steps are listed as: familiarization, identifying a thematic framework, indexing, charting and mapping, and interpretation. The data analysis process began when data was being collected by facilitating a discussion that generated rich data. This was followed by taking down observational notes and transcribing the sessions so that themes could become more evident. Certain themes and ideas (e.g. economic issues associated to the Games) became more evident during this stage due to their repetition. This process is known as familiarization. The next step involved creating codes from the ideas and concepts that were identified and forming a thematic framework. If necessary, axial codes were assigned to indicate that the idea was nested under a broader concept (e.g. economic issues being a sub-category to perception).

Table 2

Identifying a thematic framework

\begin{tabular}{|c|c|}
\hline Focus Group Extract & Codes \\
\hline $\begin{array}{l}\text { "...But that was like the most memorable. They marketed really well and } \\
\text { with their marketing campaign, it reminded me of my childhood and that } \\
\text { was like one of the most significant sports memories within my family. } \\
\text { So every time I think of the Olympics, I think of like how it brings } \\
\text { people together, how it connects people who don't even like sports, but } \\
\text { they want to represent their country and they want to show support like } \\
\text { especially how like when we saw the Raptors go to the finals. Everyone } \\
\text { stood together. And I feel like that's the same thing with the Olympics in } \\
\text { Canada, how our athletes worked so hard to help represent Canada. We } \\
\text { as citizens all support them with our whole heart. And that's what I think } \\
\text { of when I hear Olympics." (Group 4) }\end{array}$ & $\begin{array}{ll}\text { - } & \text { Childhood memories } \\
\text { - } & \text { Togetherness } \\
\text { - } & \text { National representation } \\
\text { - } & \text { Athlete dedication }\end{array}$ \\
\hline $\begin{array}{l}\text { "I think the Olympics is like a cool thing that happens, that it just like, } \\
\text { you know, everyone gets together and plays sports but like as a brand. I } \\
\text { don't have like such good associations with it like, I think there is - I } \\
\text { mean, I'm not informed or anything, but it's just like dealing with } \\
\text { countries like Russia, China, Brazil, like I think there's probably some } \\
\text { corruption that goes in to where it's hosted and like spending all these } \\
\text { billions of dollars on making a place pretty or building a stadium and } \\
\text { then they just leave. So I don't know. Like I said, I'm not informed, but } \\
\text { just my association isn't that good." (Group 1) }\end{array}$ & $\begin{array}{ll}\text { - } & \text { Togetherness } \\
\text { - } & \text { Political concerns } \\
\text { - } & \text { Economic concerns } \\
\text { - } & \text { Environmental concerns }\end{array}$ \\
\hline
\end{tabular}


"I don't know. I kind of just like I don't like watching TV that much or like, watching shows in general. But I have been thinking about the upcoming one because I used to really enjoy them and I haven't watched it for a couple years. I haven't watched the past Olympics or the one before that or barely the one before that. But I'm thinking like, well, it's it's actually fun to watch. So that's why I might want to watch it. I think there's like skateboarding in this one. Like I'm interested in seeing how it's different because it's been the same for so long. So I'm glad that they're changing stuff." (Group 2)
- Changes in media consumption

- Childhood exposure

- Sports Relevance

- Unexciting

"I agree with Tina's point in terms of incorporating like some kind of figure to commentate. In Korea, they host a sports kind of event where all celebrities and they usually have the celebrities commentating. So, if there were celebrities that were out that I connect with, having them commentate on sports, it definitely keeps it more engaging. Probably kind of highlighting the athletes and the journey because four years is a long time to train and if I kind of knew more about like what they've gone through and the hardships they went, I'd be more inclined to kind of be engaged with that." (Group 3)

- Reference groups

- Celebrity influencers

- Genuine connections

- Athlete journey's

Indexing and charting consisted of data management and is usually done by comparing and contrasting quotes, grouping similar codes together, and 'reducing' the data in a way that makes it simpler for themes to emerge. These two steps were made easier through the help of Nvivo 12. Table 3 shows an example of how indexing and charting was done during the data analysis process. Some of the themes that were identified during this process were eliminated after the frequency, extensiveness and specificity variables left them inconclusive.

\section{Table 3}

Indexing and Charting

\begin{tabular}{lll}
\hline Codes & & Themes \\
\hline$\bullet$ & Political concerns & Social Responsibility \\
$\bullet$ & Economic concerns & \\
$\bullet$ & Environmental concerns & \\
\hline & Togetherness & Sociability \\
$\bullet$ & Reference groups & \\
$\bullet$ & Childhood memories & \\
\hline & Childhood exposure & Sports Involvement \\
$\bullet$ & Sports relevancy & \\
$\bullet$ & National Representation & Patriotism \\
$\bullet$ & Athlete dedication & \\
\hline$\bullet$ & Genuine connections & Storytelling \\
$\bullet$ & Athlete journey's & \\
\hline & Unexciting & \\
\hline
\end{tabular}


Finally, mapping and interpretation were done by being analytical, understanding meaning, and forming relationships. Kreuger and Casey (2000) provide established criterions to take into consideration when interpreting coded data. These include specificity, frequency and extensiveness, big picture, and emotion. Similar to Slater \& Tiggemann (2010), this study made judgments for each theme relative to frequency, extensiveness, and specificity (see Table 4). Frequency referred to how many of the four focus groups mentioned a particular theme, extensiveness referred to how many groups members discussed a particular theme, and specificity alluded to whether or not the issues were mentioned in a personal or detailed way (e.g. 'The 'I believe' song or 'I believe in the power of you and I' from Vancouver, 2010 and the little graphic that went with that. Like literally you get chills down spine like that's I think a very prominent Olympic vision") as opposed to vague references (e.g. "I don't really have a specific memory; I just remember my mom watching a lot of figure skating"). Extensiveness was seen to be low if a theme was mentioned once, as medium when it was mentioned by 2-4 group members and high if mentioned by 5 or more participants (Slater and Tiggemann, 2009). These ratings were used for each focus group discussion that brought forth a particular theme and then an average 'extensiveness' was recorded. Additionally, some themes were identified based upon recommendations from the defense committee (e.g., time, storytelling). These did not follow the above coding process, but served to strengthen the overall representation of the data. Finally, pseudonyms were assigned to maintain participant anonymity and quotes that were used in the results and findings section were minimally edited for clarity and brevity. 
Table 4

Main themes that relate to RQ3: How does Generation Z engage with the Olympic brand?

\begin{tabular}{|c|c|c|c|c|}
\hline Themes & Frequency & Extensiveness & Specificity & Examples \\
\hline $\begin{array}{l}\text { Sports } \\
\text { Involvement }\end{array}$ & 4 & Medium/High & Specific & $\begin{array}{l}\text { "I feel like when you play the sport, it's } \\
\text { like more fun to watch it, too. Like, I } \\
\text { still like watching games and stuff like } \\
\text { that, but that's more when I have } \\
\text { people to watch with me. But I could } \\
\text { watch them alone back then, you } \\
\text { know? But since I'm not playing } \\
\text { anymore, it's kind of like I'm losing } \\
\text { interest in it." (Group 2) }\end{array}$ \\
\hline Sociability & 4 & High & Specific & $\begin{array}{l}\text { "When I was younger, like me and all } \\
\text { my cousins, we'd always watch ice } \\
\text { skating. So that's the memory that I } \\
\text { have." (Group 3) }\end{array}$ \\
\hline Time & 3 & Medium & Specific & $\begin{array}{l}\text { "Same thing, YouTube, short clips, } \\
\text { highlights. I used to watch full games } \\
\text { live streaming, but I can't do it now } \\
\text { because of time constraints. So if I get } \\
\text { the time, I just YouTube it or } \\
\text { something." (Group 2) }\end{array}$ \\
\hline $\begin{array}{l}\text { Celebrity } \\
\text { Influencers }\end{array}$ & 3 & High & Specific & $\begin{array}{l}\text { "Just find like, for example, maybe } \\
\text { like, celebrity endorsement, maybe like } \\
\text { a lot of brands, a lot of brands pay so } \\
\text { much money to have commercials on } \\
\text { the Olympics. I feel like they could - if } \\
\text { they really want to work with someone } \\
\text { they could do it as like a mutual thing." } \\
\text { (Group 1) }\end{array}$ \\
\hline Storytelling & 2 & Low & Specific & $\begin{array}{l}\text { "I like creative storytelling. I'm really } \\
\text { open to other cultures, too. So it would } \\
\text { be cool to, like he was saying, it would } \\
\text { be cool to have like have the } \\
\text { opportunity, not like from a marketing } \\
\text { perspective, but from a world } \\
\text { perspective to showcase the culture and } \\
\text { how this person rose to compete at the } \\
\text { sport in a way that might differ from } \\
\text { how somebody competes in the sport in } \\
\text { Canada" (Group 4) }\end{array}$ \\
\hline
\end{tabular}


"I think if the Olympic brand could really bring about international unity, because I think that's something that our generation is very interested in and it's it's kind of disenfranchising at this point with people like Trump and those sort of things. I think if they could almost like bottle like unity and harmony, it sounds like it's very like way up there and ambiguous. But I think if if they could really focus on the international cooperation and the camaraderie and talk about it, talk about that component of it, it might be something that would be welcome in today's day." (Group 4) 


\section{Results}

This chapter begins with a profile of Generation $\mathrm{Z}$ sport consumers and then provides participant insights relative to brand awareness (RQ1), brand perception (RQ2) and brand engagement (RQ3).

\section{Generation Z Sport Consumer Profile}

The Generation $\mathrm{Z}$ sample studied in this research reported varying degrees of Olympic fandom and consumption, with a majority of participants reporting greater involvement with the Olympics during their youth and less interest as a young adult. Stewart, Smith and

Nicholson (2003) devised a classification system to organize varying types of sports consumers. This framework was used to help classify distinct types of participants based upon their stated relationship with the Olympic Games. Four categories were established including: committed fans $(n=2)$, casual audience $(n=9)$, bandwagoners $(n=3)$, and participants that presented as uninterested $(\mathrm{n}=8)$ (see Figure 1). It is important to note that this breakdown was found to be a close representation of sports fandom at broader societal levels. For example, a 2017 Gallup poll found 59\% of Americans identified as sports fans. Of the participants in this study, $63 \%$ reported identifying as a sport fan with $9.1 \%$ identifying as Committed fans based upon their vast Olympic knowledge and emotional attachment to the Games. This segment easily defined themselves through team success. Casual fans (40.9\%) primarily sought entertainment from the Olympics and their support was contingent on the success of the team. Bandwagoners $(13.6 \%)$ were seen to consolidate their social networks through watching the Games. They enjoyed the excitement obtained through watching sports with others. Uninterested participants (36.3\%) were named as such since as the name suggests, they were not interested in the Olympic Games or sporting activities in general. Each participant segment was created and coded based on their reported connection to the Olympic brand, the benefit they sought through Olympic consumption, and their level of Olympic consumption. These 
classifications have been used to organize the research findings and provide a deeper level of analysis.

\section{Figure 1}

Participant Classification

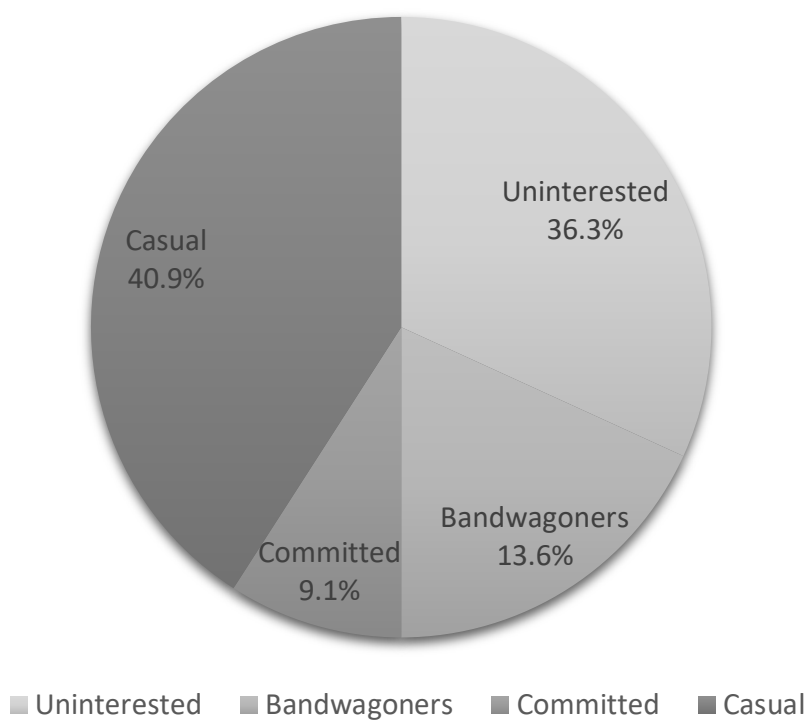

Sports media consumption. In terms of sports media consumption, participants declared social media a prime source for sport content. Notably, one respondent $(n=1)$ indicated that they were not a social media user, but had a cable subscription at home. When asked about where sports news/insights were gathered from, $86 \%$ of participants mentioned the use of social media as their primary source $(n=19)$. Within this, Instagram was found to be a primary resource ( $n=14)$, with participants also noting the use of group chats $(n=6)$ and Reddit $(n=1)$ as tools for sports news consumption.

\section{Gen Z Awareness of the Olympic Brand}

The first research question sought to explore the level of awareness Generation $\mathrm{Z}$ had of the Olympic brand and identify key factors that affect Olympic awareness. Generally speaking, the overall level of awareness among this group was found to be quite low. Notably, 59 percent $(n=13)$ of participants reported that they were completely unaware that 2020 was a 
planned Olympic year for the Summer Games. Yet, $77 \%(n=17)$ reported that they actively watch or play sports, basketball being the most popular spectator sport $(n=13)$.

Some of the different facets that were brought forth in discussions surrounding awareness included: athlete identification, frequency of Olympic cycles, sponsorships, social currency and the impact of hosting the Games.

Athlete identification. Conversation regarding favourable athletes showed that most participants had an enhanced familiarity or preference for athletes from sports leagues such as the National Hockey League (NHL) or the National Basketball Association (NBA). Only a few participants were able to highlight a favourite Olympian, illustrating a low awareness of Olympic athletes as a whole. Usain Bolt's 2008 victory was mentioned several times $(n=5)$. He was viewed by participants as an athlete that broke all boundaries and redefined what it meant to be a runner. Andre De Grasse was brought up by a participant $(n=1)$ that was classified as a bandwagoner in reference to his second-place finish to Usain Bolt in the 200m during the Rio Games. Tessa Virtue and Scott Moir were mentioned by two participants $(n=2)$ deemed casual fans and one participant $(\mathrm{n}=1)$ labelled a committed fan. The ice dancers were viewed as highlevel athletes, in reference to their 2010, 2014 and 2018 Olympic performances. A casual fan participant captured the sentiment noting:

Oh, Pyeongchang. Yes, the Canadian team basically wiped everyone. Or like in figure skating and ice dancing. I believe Tessa Virtue, Scott Moir and Patrick Chan won pretty prestigious medals. I think it was either first, second, or third place. So, it made me feel proud that I was Canadian. (Logan, Casual fan).

Another participant, who identified as a casual fan, brought up the story of a former Olympian from India that won a gold medal in archery during the 2008 Summer Olympics, noting that this athlete had been portrayed by the media as a representation of sporting excellence for India. Simone Biles and Laurie Hernandez were similarly described as being "very good" athletes by participants based upon their respective media portrayals. Kyle, a committed fan, referenced several Olympians that qualified from 2010 onwards due to his 
commitment to the Olympic Games. It is noteworthy that many athlete references mentioned by participants were dated. References to athletes that participated in the 2010 Olympic Games hosted in Vancouver, Canada seemed to be particularly memorable among this Canadian audience.

Frequency of events. During the focus group discussions, it became evident that when participants $(n=6)$ made reference to the frequency of the Games, they were under the impression that the Olympic cycle reoccurred every four years. There was a distinct lack of awareness around the Winter Games, the Youth Games, or the Paralympics amongst this audience. When asked about their Olympic consumption in comparison to other sporting events, one participant noted:

I feel like it is different because sports consumption happens like all year round. They have different seasons. They go longer periods of time versus the Olympics, which is a bunch of sports compacted in a short period of time for once every four years. So there might be high consumption during two or three months in the year and then there's literally nothing for like three or four years, so there is a huge difference. They don't maintain that excitement and that awareness in between the games. (Nia, Casual Fan)

Sponsorships. Amongst the uninterested and bandwagoner consumer groups, when asked about Olympic sponsor recall, answers ranged from Adidas, UNICEF, McDonalds, Pepsi, Red bull and Coca-Cola. No participants were aware of the fact that McDonalds discontinued their Olympic long-standing sponsorship deal three-years ago in 2017. Only one respondent could recall seeing any Olympic marketing content on their social media platforms. A majority of participants were able to recall seeing the Olympic logo on a McDonalds cup. Amongst casual fans, there was mention of Gatorade, Audi, McDonalds and Nike. One participant recalled seeing an advertisement from "credit card companies" during the 2018 Pyeongchang Games and was reminded of Visa being an Olympic sponsor. A committed fan correctly named both Procter \& Gamble and Visa as official Olympic sponsors, but could not recall any digital Olympic content associated with these brands. The other committed fan was 
aware of several Team Canada sponsors such as Tim Hortons and Hudson Bay, but none of the TOP's were mentioned.

Participants agreed that sponsors needed to position themselves as more relevant to younger demographics. They believed that this would increase their overall awareness of the Olympic brand. Further to this, marketing the Games on social media platforms such as Instagram was highly stressed by all focus group participants as a way to increase their overall awareness.

Social Currency. The concept of "social currency" emerged as an important factor that participants linked to their awareness of the Olympic Games. When asked if participants would be more likely to watch the Olympics if their friends and family encouraged them to do so, all participants $(\mathrm{n}=22)$ agreed to some extent, regardless of their 'sports fan' classification. Several respondents mentioned that if their friends or family were talking about a specific game, it would become "annoying" if they were unable to contribute to the conversation. It was also mentioned that it was more entertaining to watch sports if there was someone to discuss the events with. Several references were made regarding the sociability associated with the Toronto Raptors games and how everyone [Canadians] came together to watch the team during their historic 2019 playoff run. Although committed fans were more likely to be interested regardless of the social currency surrounding a sports event, casual audiences, bandwagoners, and uninterested audiences reported being much more likely to be engaged with sporting events if they were perceived to be relevant to broader societal discourse as illustrated by Anne:

It's kind of hard to like get into it if you're alone, but if someone's constantly talking about it with you and keeping up with you, it's more fun because you get to talk about it, right? (Anne, Casual fan)

There were some comments that related to the 'Fear of Missing Out' and its effect on content consumption. On the subject of Toronto Raptors games, a participant classified as a bandwagoner noted that: 
I think it's like everyone was possibly talking about it. Like did you know or did you see what happened last night? I would just get annoyed and I would just watch it. (Kenneth, Bandwagoner).

Similarly, several participants $(n=4)$ mentioned that during the 2019 NBA play-offs, games were watched solely for the "fandom mentality" and to keep up with interested family and friends.

Impact of hosting the Olympics. When reflecting upon their connection to the Olympic Games, participants often evoked memories of their childhood. Since data was collected in Canada, there was a strong recall of the 2010 Winter Olympic Games hosted in Vancouver, Canada $(n=5)$ as well as mention of the 2015 Parapan-Am Games $(n=2)$ that were hosted in Toronto, Canada. Kyle mentioned that during the 2010 Games, his teachers cancelled exams to watch Canada's performance at their school's auditorium which created a "hype" that made the events a lot more enjoyable for audiences. One casual fan mentioned that they were a lot more inclined to visit an Olympic host country after being exposed to its culture through a mega sporting event. Participants also noted that when the Olympics were being hosted in Canada, they ignited an outpouring of national pride among citizens. This was viewed as an appealing quality that also peaked their interest in consuming the event.

Exchange from Group 4:

(Nadia, Uninterested): “The opening ceremony in 2010. That was one that I actually watched the whole way through because I remember at school, everyone was excited for it and then when it actually happened, we were all like "wow". This is in Canada, it's basically in my house."

(Kyle, Committed Fan): "Yeah, I remember watching the torch run across Canada and it was like, shocking."

\section{Gen Z Perceptions of the Olympic Brand}

The second research question sought to explore Generation $\mathrm{Z}$ perceptions of the Olympic brand. Participants in this research were found to exhibit varying perceptions with regard to the Olympic brand, with little overlap between the four fan segments. In order to 
identify basic perceptions of the Olympic brand, participants were asked to provide the first words that came to their minds with regard to the Olympic brand. This resulted in the emergence of four themes: corruption/social responsibility, sport achievement, patriotism, and entertainment.

Corruption/Social Responsibility. The most common perception amongst all participant segments related to the social, political, and economic challenges that have been associated with the Olympic Games. Corruption and overspending were mentioned by an uninterested respondent, who explained that they were not fully informed with specific details but perceived the Olympics through the negative lens of corruption, nonetheless. A participant classified as a bandwagoner was particularly interested in economic development and perceived the Games as a poor representation of fiscal responsibility. Minimal returns on taxpayer investment, infrastructural damage, and the poor use of prime real estate were all topics that the participant associated with the Olympic brand. Casual fans generally appeared to have stronger associations and opinions about the Olympic brand compared to other consumer groups and were able to speak about their perceptions in greater detail. This is evidenced by the following brand sentiment:

I'm going to be honest. Personally, I think about the corruption and stuff like that because personally, I like to read geopolitics and stuff like that. So, even today, you hear about the corruption from the past and also, for example, for Rio, all the cost overruns and all the stuff that still impacts [the country] today. Even stuff about the labor and then Tokyo coming up, you know, you hear about like how coronavirus is going to affect it too. Like, I wouldn't say just corruption, I guess like the politics surrounding it. (Rashid, Casual fan)

Among committed fans, there was mention of the lack of athletic integrity associated with the Olympics and how this affected Olympic perception. "It sort of betrays us. Just with the lack of athlete integrity and the scandal with Russia. That was a really big issue and of course it had a lot of backlash". (Carla, Committed Fan). When Kyle was asked about how his 
Olympic consumption varied in comparison to other sporting events, he mentioned a noteworthy issue which was seen to be related to their brand perception.

I feel like there was so much backlash from Rio; there was so much that made me just not want to watch those Olympic Games because it was super corrupt and there was so much happening with like in terms of news and, for example, I was so frustrated with the fact that Canada was still allowing their athletes to even consider swimming in the rivers, knowing that they would be so polluted and they would get so sick from that. (Kyle, Committed Fan).

Sports Achievement. The Olympic brand was viewed as the peak of athletic success and a personal goal for one committed fan in light of their own sporting aspirations. This sentiment was captured by the following participant who noted, "I think about all of the athletes, their comebacks, their passion, the drive and how much time and effort they put in to just hold that Olympic gold”. (Kyle, Committed Fan). A bandwagoner mentioned that the Olympics were "...the real deal, [the] Super Bowl of all the sports combined". This statement was followed by a participant mentioning their sentiment on Olympic athletes by stating that they were the "Best of the best coming together". For others, the Olympics and their audiences were seen to be prestigious, but in an elitist and pretentious way. A casual fan noted "I feel like every country just does it just to kind of show off and for their ego" (Maya, Casual Fan). When asked about their immediate association to the Olympic brand, a participant stated:

Basically, winning and country status, I guess, because of when people have the most medals, they're just like looking down at everybody else who doesn't have like America usually has a lot because they send like the most athletes. (Alex, Uninterested)

In the same vein, an uninterest participant noted that they associated the Olympic Games with a niche and intellectual audience. This respondent believed that the Olympic audience was a distinct group of people that excelled in various aspects of their lives and took pride in their outstanding talents and abilities as evidenced in their statement:

I'm just thinking of people who I remember in high school who were just obsessed. It's a certain type of all-around kind of [a] person, who excels in all different things. Like, they're glued to the Olympics when it's on and they're just so hyped. So yeah, like super preppy people watch it. They would play one instrument. They would be good at every class. They would be super uppity. (Laura, Uninterested) 
Participants clarified this was due to the perceived prestige that they believed came with Olympic success.

Patriotism. National pride and patriotism were consistently associated to the Olympic brand and its consumption. While some participants stated that they would watch individual sports and athletes, many agreed that watching the Olympics was about exhibiting support for a chosen country or team, especially if they were excelling in a particular sport.

Exchange from Group 4:

(Jermaine, Uninterested): “...I would watch a lot more Olympics because it's more like, I guess it's a nationalism type of event. Like you watch Canada, my household would support Germany, so we'd watch the Germany Games. Same with soccer. So I think that compared to other sports, the Olympics are a big national exposition"

(Rashid, Casual Fan): "I would agree because like I don't know, I think I'm a pretty patriotic dude. So I like to watch just all the Canada games I can. It only happens every four years."

(Kyle, Committed Fan): "Yeah, same for me. It's super patriotic, I feel very Canadian."

Similarly, another uninterested participant stated that Olympic consumption was linked to tradition and respective patriotism. This was captured by one participant that noted: "I think it's more traditional and like, you know, you're coming for your country. You've gotta come for your country. It's more traditional and loyal". Although many participants expressed their intent to support specific countries during the Olympics, it was noted that if athletes were breaking records (i.e. Usain Bolt and Michael Phelps), the lure of witnessing incredible athletic talent could usurp country affiliations and make participants more likely to support the contributions of superstar athletes.

Entertainment Value. Some bandwagoners and uninterested audiences had a lighthearted approach with regard to their brand associations to the Olympic brand. The entertaining nature of the opening and closing ceremonies were mentioned by these participants $(n=3)$ who 
associated the Olympics with a grand and memorable spectacle that was sometimes considered to be more interesting than the Games themselves.

I always think the opening and closing ceremonies are fun to watch. Like a lot more fun than the sports, in my opinion. Yeah, I remember London had a cool opening ceremony. Rio had a cool opening ceremony, closing ceremony in Beijing I remember watching. So, yeah, those are always cool and artistic. (Joey, Uninterested)

Besides the opening and closing ceremonies, entertainment was seen to be severely lacking from the Games. There were several references to Super Bowl advertisements $(n=6)$ and how a similar appeal was lacking from the Olympic Games.

So, I feel like the Super Bowl, they have all those funny commercials and skits that are a part of the culture of the Super Bowl. When I think of the Superbowl I don't think anything about football, I think of halftime and I think of the energy and the advertisements. I mean like, millions of millions of dollars. It [the Olympics] lacks all of it, like I'd never hear about it. So, if you get someone cool, someone current like musicians or some other athletes who are playing and want [to] make a quick buck. It's a brand that has kind of gained a repertoire. They're not [a] bottom of the barrel [brand] that nobody wants to associate with. So, it shouldn't be hard to get someone cool just to associate with. (Laura, Uninterested).

Additionally, participants mentioned that sporting leagues such as the Ultimate Fighting Championship (UFC) and the NBA were entertaining to watch because they have an element of rivalry and drama associated with them, which participants believed the Olympic Games are lacking. Rivalries and competition between different cities, countries, and teams were mentioned as way of getting audiences excited for big events. The Canada vs. United States rivalry was one that was mentioned several times as a "big game", but the Olympics were largely viewed as being unexciting due to a perceived lack of exciting storylines. It was generally agreed upon that the Olympics need to have an increased entertainment value if they are to attract and retain younger audiences. As Hannah articulated:

I think the unfortunate thing about the Olympics is that apart from the corrupt stuff and whatever, it's actually kind of like a wholesome way to give people a way to watch sports. Like, I'm thinking, how can people watch and get so hyped up [for the] UFC, but not Olympic boxing or the NBA, but not Olympic basketball. It's because those things, kind of make a show out of it in a way that I don't think the Olympics really does. Which is kind of pure, but it just doesn't - I don't know, maybe it doesn't work. (Hannah, Uninterested) 
Hannah mentioned her wavering interest towards the Olympics due to its lack of appeal:

It's just hard to say because I think that everybody pretty much knows about the Olympics. I don't think anybody doesn't know what it is. It's about being interested. There's a lot of stuff that's just not very interesting to watch. I think like throwing. I mean, like, actually, am I a fan of throwing a ball? You know, is speed walking an Olympic sport? Or like, running and biking and you know, you could watch a couple highlights going over the finish line, but I'm not going to watch it for an hour or something. (Hannah, Uninterested)

It should be noted that introducing new sports such as rock-climbing and skateboarding was seen to be of interest to this sample.

For me like skateboarding was something I was really into. And this year in the Olympics, skateboarding is a sport. So, I would be more inclined to watch that sport just because it's just it's a sheer like new sport that they've introduced. (Rita, Casual Fan).

\section{Generation Z Olympic Brand Engagement}

The final research question was developed in order to better understand how Generation $\mathrm{Z}$ currently engages with Olympic content and determine what their general preferences are. To start this discussion, questions such as "How does your Olympic consumption vary from other sports, if at all" and what would you do if you had the option of making the Olympic brand more appealing" were asked. Several noteworthy themes emerged from these conversations including perceived challenges to engagement like time, and athlete identification, as well as opportunities for improved engagement with themes emerging around the concepts of unity, celebrity influencers, sport involvement, and sociability.

Time. Many participants stated that they did not have enough time to catch full sporting events, even on streaming platforms. Full games were only watched when they were considered to be important. Otherwise, it was generally agreed that catching highlights on social media was the most popular way of consuming sports content. Instagram, in particular, was repeatedly mentioned among all participant segments as an important platform for Olympic content distributors to take advantage of. Participants expressed that sports news and insights were 
typically gathered from different Instagram pages such as Bleacher Report, TSN, and Sports Net. House of Highlights was mentioned as a YouTube channel that was popular for catching game highlights.

I don't watch a lot of sport videos. I just watch highlight videos, maybe the most popular ones. I think snowboarding or like other winter sports are just ones I gravitate towards. (Ali, Bandwagoner)

Only one respondent $(n=1)$ claimed that they used an app to consume sports content; this was not considered to be a favourable way of watching full game content due to the small screen size. Concerns surrounding the length of Olympic broadcasts was also discussed by participants, particularly the challenge of a condensed schedule fit into just two weeks of programming. It was agreed that the two weeks of Olympic coverage provided once every two years made it difficult to develop broad based fandom and fan identity. Participants believed this schedule rendered the Olympics irrelevant outside of this small window and in nonOlympic years. One participant drew a contrast with professional sport presentations noting:

The NBA is spread out, like you can come home from work [and] watch a game. It's not going to be consecutive, like so much time. A working adult doesn't have time to come home from work and watch so much of the Olympics and then also take care of your kids and cook food. (Ali, Bandwagoner)

Storytelling. Connecting Olympic athletes to audiences was another important finding.

Most participants agreed that they did not know much about Olympic athletes and would be more inclined to watch their performances and support them if they formed some sort of connection to them prior to the Games. One uninterested participant noted:

I think if there was more opportunity to see really the story of athletes like you're saying, like even outside of the country, it'd be cool to see profiles of some of the hopeful stars from all different countries that are going there. (Jermaine, Uninterested)

Once again, Kyle (committed fan) was the only participant that was aware of the media content that is being created to highlight/promote the stories of Olympians. He specifically brought up RBC athletes (a program that helps to financially support Olympic hopefuls). 
Despite his awareness of the program, he clarified his perception that it was very poorly marketed on social media channels.

With Netflix being a popular streaming platform for content among this generation, it was recommended by many participants that informative, yet entertaining content involving Olympians, their personal stories, and build-up to the Games be posted on either Netflix or YouTube for accessibility and viewing convenience. Kyle shared his thoughts on the importance of athlete identification:

Like Eddie the Eagle, in Calgary. I mean, you know, everybody knew he was going to lose. Like, there was no question whether or not he was going to lose it. Everyone was rooting for him to even just go over the jump because he just was this guy who really wanted a chance to be in the Olympics. I know I keep going back to that, but it was like he had more viewers in those Olympics than any other athlete. Just purely because he had a story behind him. (Kyle, Committed Fan)

In this case, it should be noted that Eddie the Eagle competed in the 1988 Olympic Games, well before any of these participants were born. This athlete's Olympic journey was captured in a 2016 biographical film directed by Dexter Fletcher, and featured on Netflix.

Unity. The concept of international unity was introduced during multiple focus group discussions as it seemed to resonate with several participants. It was stated that the current political environment was lacking international unity and the Olympic Games could potentially use this to their advantage by connecting with audiences through this narrative. Emphasizing the concept of bringing people together through their individual patriotism and creating a joint force was viewed as an appealing concept to this age cohort. As Jermaine noted:

I think that especially within the age group that you've selected, I think if the Olympic brand could really bring about international unity, I think that's something that our generation is very interested in and it's kind of disenfranchising at this point with people like Trump and those sort of things. I think if they could almost like bottle unity and harmony, it sounds like it's very way up there and ambiguous. But I think if they could really focus on the international cooperation and camaraderie and talk about it, talk about that component of it, it might be something that would be welcomed in today's landscape. (Jermaine, Uninterested). 
Celebrity Influences. When asked to ponder recommendations for improved engagement with the Olympic brand, participants suggested several overlapping strategies. The most popular recommendation among this sample was to use famous athletes and celebrities to promote the Olympics. Many participants agreed that the use of relevant celebrities such as Kevin Hart, Dwayne Johnson, and Beyoncé would be beneficial before and during the Olympics, believing this would raise awareness and create anticipation. In the same light, it was mentioned that having famous athletes such as Michael Phelps commentate Olympic events and run campaigns on social media would be an effective strategy to improve brand awareness and engagement. As an example, one participant mentioned that influential athletes like Christiano Ronaldo could run social media contests and incorporate all-inclusive trips to the host country as prizes. Social media celebrity takeovers, entertaining social media advertisements, the general use of pop-culture, and content virality were all believed to be effective communication strategies that could benefit the Olympic brand. It is important to note that most of these strategies are already being implemented. This sample offers evidence that the messaging around these brand activations may not be reaching the Generation $\mathrm{Z}$ audience as effectively as marketers hope.

Sports Involvement. Within the context of participants' relationship with sport over the course of their life, participants offered insights on key motivators relative to their general sport engagement. Committed fans $(n=2)$ were still actively playing and watching sport, both now and during their childhood. Casual sports fans were relatively active, but majority still stating that they were still actively playing and watching sports. One participant said that they played baseball during their childhood but stopped when all of their friends left the team. Another participant was particularly excited about skateboarding being introduced into the Olympics since it was a sport that they had previously been involved with. Bandwagoners were 
seen to be less involved, with some stating that they still played sport, even though it was not very regular.

When asked if anyone grew up watching sport, several bandwagoners $(n=3)$ said that they watched the Olympics growing up with their families. Uninterested participants claimed that they watched sports such as soccer or basketball, but none of them were currently involved in playing sport. Only one participant $(n=1)$ mentioned that they played basketball when they were in high school but noted they had discontinued playing in post-secondary school. Other participants reported to be completely uninterested in both watching and playing sport. It can be deduced that a lack of sports exposure during childhood and adulthood led to disengagement with the Olympic Games, while active sport participation seems to increase Olympic consumption. The greater the sport participation, the greater the chances of Olympic consumption as evidenced by this participant's comment:

Also, I feel like when you play the sport, it's more fun to watch it, too. Like, I still like watching games and stuff like that, but that's more when I have people to watch with me. But I could watch them alone back then, you know? Since I'm not playing anymore, it's kind of like I'm losing interest in it. (Tommy, Casual Fan)

Kyle made an important recommendation based on his personal experiences with the Olympic brand, mentioning that childhood exposure to the Games at schools and camps is a crucial entry point for children to become Olympic enthusiasts. "When catching live broadcasts on television was the popular way of consuming sports content, schools and camps would encourage children to watch the Olympics" he noted, "particularly when Team Canada was playing". This created excitement and awareness of the Olympic brand in childhood. Kyle astutely noted that since media disruption has changed consumer content consumption, these early bonds with the Olympics are more difficult to establish. He believed this change was impacting broader views of the Olympics and rendering them as a less entertaining activity to do with children. Improved engagement with children may, therefore, exist as an important strategy for the Olympic brand to consider moving forward. 
Sociability. The social element of sport was highlighted multiple times as participants referenced the role of parents, grandparents, and friends relative to their involvement with sports. This was particularly applicable to childhood involvement, but also discussed relative to participants' current sports involvement. Participants linked the importance of social elements to their active sport participation. Some participants stated that they played several sports at some point in their life, but became less active when their friends left teams. The ones that were still actively involved with sport mentioned being part of a team on-campus or a member of a larger sport community. When asked about their favourite Olympic memories, a theme that consistently emerged was the feeling of togetherness that came with watching the Games with family and friends. Many participants could remember a time where they watched Olympic broadcasts with their families on television. As one participant noted:

I'm not really tied to the Olympics so much. I guess a good memory would be like how my family used to gather and friends used to gather to watch it when we were younger. So, it was kind of like a fun thing to do. Just watching sports. (Tommy, Casual Fan) 


\section{Discussion}

The purpose of this research was to explore what the Olympic brand means to a Generation $\mathrm{Z}$ audience and uncover how attitudes, subjective norms, and perceived behavioural control influence this demographics' brand perception, brand awareness, and brand engagement with the Olympics. Findings suggest this age cohort has fond memories of the Olympic brand from their youth but have largely disengaged with the brand as young adults. This sample reported largely negative brand associations, a low awareness of the Olympics, and linked accessibility challenges to their disengagement with the brand.

In the last decade, the sports industry has undoubtedly seen a shift in its culture due to the advancements in digital media and technology. The importance of production, delivery, entertainment value, and overall fan experience are now highly emphasized due to their direct link to corporate profitability (Andrews and Grainer, 2007). Social media plays a key role in this shift since it has challenged the role of traditional television by introducing new content distribution and consumption strategies. The phenomenal growth and popularity of social networks has attracted a wide range of audiences and redefined the way sporting events are experienced among increasingly segmented audiences (Tang and Cooper, 2018).

Generation $\mathrm{Z}$ has been found to be a particularly challenging demographic, given the fact that digital technology has been highly integrated into most aspects of their lives (Duffet, 2017). From socializing, to exercise, much of this demographic's behaviour is digitally mediated online (Scroth, 2019). Beall (2016) argued that if a brand does not meet Generation Z's expectations, it runs the risk of becoming irrelevant in today's highly fragmented media environment. To explore the changing sports consumption habits amongst the youth, this study put the relationship between Generation $\mathrm{Z}$ and the Olympic brand under a microscope. In doing so, it revealed the areas where the Olympic brand could be refined. Brand managers must constantly adapt to change; this includes changing consumers, values, competitors, and 
preferences (Kapferer, 2008). The results of this study indicate that although the Olympic brand has been trying to reach the youth through the use of digital and social media, their efforts have not been very effective. This highlights the essential role of strategic marketing, not only to the sustained profitability of the Olympic brand, but also its legitimacy moving forward.

\section{Gen Z Perceptions of the Olympic Brand}

Consumer perceptions and attitudes are formed through personal experience, group associations, and influential others or perceived experts (Ewah et al., 2014). TPB literature explains how attitudes are directly related to the formation of intentions, which can positively or negatively affect individual behaviour. From this assessment, it is apparent that many Generation $\mathrm{Z}$ consumers do not have a favourable perception of the Olympic Games. A majority of participants associated the Games with corruption, overspending, and a lack of social responsibility. These results appear to validate the work of Kenyon et al. (2018) which found that none of the working principles of Olympism (collaboration, autonomy, universality, social responsibility and solidarity) were present in their brand images. Kenyon et al. noted that brand image inconsistencies are an identified barrier to a brand success (Kenyon et al., 2018). This study confirmed that the working values and principles of Olympism are not being reflected in audiences' perception of the Olympic brand.

\section{Generation Z Awareness of the Olympics}

With committed fans being an exception, there seems to have been an overall lack of awareness surrounding Olympic events, athletes, sponsors, marketing efforts, and overall accessibility. Although the Olympic Games have a digital presence on Instagram, Facebook, and Snapchat, the results show that the content is not reaching Generation $\mathrm{Z}$ effectively. Drawing from Azjen's (1991) TPB once again, perceived behavioural control largely dictates consumer intention and behaviour. In line with this theory, this study indicates that respondents did not try to access live Olympic broadcasts online because they were not aware of its 
availability. Several participants stated that streaming sports online can be difficult due to legal concerns, and the Olympics were no exception. However, it was noted that the likelihood of seeking online content significantly increased when there was 'buzz' surrounding the brand or the event. The success of the Toronto Raptors during the 2019 NBA season was consistently mentioned as an exciting time for Canadian sports. Participants were eager to engage with content related to the Raptors due to its relevancy and the collective enthusiasm associated to their play. Studies have shown that content is most shared when it triggers an emotional response or when it's deemed useful (Ecker and Bolls, 2011). Other social motives that contribute to electronic WOM and sharing include the need to validate ones' social status or to enhance perceived expertise of a specific topic, this is also known as social currency (Yuki, 2015). According to Yuki (2015), social currency is achieved through sharing or creating content that makes the sharer "look good"; this includes content that makes individuals look aware, funny and intelligent. The collective perceived absence of relevancy and entertainment value associated with the Olympic brand seems to have left many participants uninterested in engaging with Olympic content online. When asked if participants would be more likely to engage with Olympic content if their friends and families encouraged them to do so, most participants agreed to some extent. Thus, social currency is seen to be an important variable to consider for Olympic marketers.

\section{The Impact of Echo-Chambers}

This work also highlights the role of social media in the spread of news. A news item can be spread across the world and shared amongst millions of people in a matter of minutes through the use of social networks (Lee and Ma, 2012). Studies of online behaviour have shown that people tend to seek information that supports their current belief systems; this is more commonly known as confirmation bias (Mocanu et al., 2014; Bessi et al., 2015). This phenomenon largely affects engagement with content on social media. Certain content is 
selected and shared amongst like-minded communities, which enforces group polarization (Del Vicario, 2016). Acceptance of information is correlated to social norms and how strongly the news resonates with the community's beliefs (Del Vicario, 2016). The aggregation of shared beliefs within a cluster of like-minded individuals creates echo-chambers that further reinforces the selected narrative. Generation $\mathrm{Z}$ is known to value equality, social responsibility, authenticity, and inclusivity (Scroth, 2019). In relation to the Olympic brand, scandals associated to doping, corruption, overspending, and environmental damages appear to be more 'visible' to this age cohort since the public dismissal of these notions tends to reinforce their values, making these notions more apparent within their respective communities.

\section{Generation Z Sport Involvement}

The Olympic movements' mission statement places emphasis on promoting Olympic values in society, with a specific focus on youth (IOC, 2020). Hence, it can be assumed that the organization recognizes the value of involving the youth in sporting activities because this has a direct influence on the vitality of the movement. However, there has been a general decline in sports participation amongst North Americans; most youngsters opt out of sports by the age of thirteen (Mulcahy, 2017; Bogage, 2019). Factors that contribute to this decline include the increase in cost, increase in competition, and a lack of interest and/or time (Bogage, 2019; Mulcahy, 2017). Many schools and parents are fixated on the concept of winning and "becoming the best", and this hyper-competitive environment has become a demotivator for sports participation (Strashin, 2016). The lack of interest stems from the absence of role models and the loss of sociability associated with being involved in organized sports (Strashin, 2016).

When participants of this study were asked about their relationship with sports, many stated they were involved in sporting activity as a child but were no longer in sport due to a lack of time or interest. It was also identified that uninterested participants were not exposed to or encouraged to be involved in sports during their childhood. This is consistent with 
Sanchez-Miguel et al.'s (2013) study that shows a positive relationship between parental sports motivation and its effect on children's long-term sports motivation and enjoyment. Since Olympic sports are the 'product' that is being offered, it is important to ensure that it is appealing for audiences to consume. A general lack of societal interest and appreciation for sports exists as a serious consequence for the Olympic brand, given sporting excellence and sportsmanship are at the heart of the organization.

Despite declining sports participation, it is important to note that patriotism was a strong motive associated to Olympic consumption. Most participants, regardless of their sports consumption levels, agreed that the Olympics were about showing support for their respective home countries and origins. Since data was collected in Canada, there was a strong recall of the Vancouver 2010 Winter Games. The Vancouver Games were found to have a notable impact on this samples' Olympic associations and memories. Although previous studies indicate that Generation Z is not particularly nationalistic (Grow and Yang, 2018), international sporting events have shown to increase the sentiment of patriotism amongst many consumers (Kim et al., 2013). This is especially apparent when the country being supported is winning since this allows individuals to feel vicarious achievement. This phenomenon is also known as "basking in reflective glory" (Cialdini, 1976). This finding could lend support to the impact of hosting Olympic Games.

\section{Media Consumption}

Relative to Olympic consumption, there were slight discrepancies noted in the findings between how this population reported their current Olympic consumption strategies and their recommendations for improved engagement with the Olympic brand. Many participants agreed that the Olympics could benefit from an increased emphasis on concepts surrounding internationalism, global unity, and togetherness, even though their respective patriotism was a strong motivator for Olympic consumption. Although universality and collaboration are two 
of the five working principles of Olympism (IOC, 2020), Kenyon et al. (2018) stated that none of these values were found in the brand images that they recorded in their research. The results of the current study appear to confirm these findings.

Additionally, the growth of technology has challenged traditional distribution and consumption of sports content. Attention spans have decreased, and media has become incredibly fragmented (Neilsen, 2018). This fragmentation has increased competition and has made it difficult for sport brands to stay relevant amongst the youth. However, Robles (2018) asserted that sports are not losing their popularity, rather the way they are being consumed is changing. A study by Google (2018) showed that watching longform sports is considered to be a commitment, especially if conflicting time-zones are involved. Hence, many sports consumers are shifting towards catching highlights. Between 2017-2018, the watch time of sports highlights on YouTube increased by $80 \%$ (Google, 2018). This research was strongly reflected in this study since many participants stated that they mostly watched sports highlights on social media due to time constraints - unless the game was perceived to be very important. Sports fans want to watch content on their own terms, which includes the ability to watch it anywhere, at any given time. This makes it pivotal for sporting brands to become dynamic and flexible in their distribution strategies so that they can provide the "full experience" (Robles, 2018).

Further to this, second-screen behaviour is seen to be an important element of sports consumption amongst the youth. Ninety-five percent of the Generation Z population stated that they used another device while watching television (Statista, 2018). Eighty percent of sports viewers say that they use their mobile devices while watching live sport (Google, 2018). Messaging friends about the game, looking for related content, reading the news, and scrolling through social networks were some of the uses of their second screens (Statista, 2018). This brings back the importance of social currency since the lack of community surrounding an 
event can have consequences on its digital engagement. There is a higher probability that viewers will consume content that makes them feel like they are a part of a larger community that they can engage with online (Matrix, 2014). Modern sports fandom goes far beyond just the game itself. There is an increasing need to consume not only entertaining and interactive sports content, but content that allows fans to feel socially connected (Smith and Smith, 2012). Azjen's TPB (1991) mentioned how social norms effect the intention to exhibit certain behaviours. Through the use of this theoretical framework, participants of this study confirmed that social involvement and content accessibility would affect their Olympic consumption. It is important to ensure that Olympic content is made available where Generation $\mathrm{Z}$ wants it and it is engaging enough to retain their sometimes fleeting attention spans.

\section{The Role of Sponsorship}

Pederson (2014) reported that the penetration, scope, and scale of social media reach has transformed global sport. As social media use increases and replaces the role of traditional television, the role of digital consumption and its effect on sponsorship needs to be explored. Commercial sponsorship is one of the biggest sources of revenue for the IOC, after broadcasting rights (IOC, 2020). The IOC claims that sponsorship activations enhance the Olympic experience and enables youth to discover Olympic ideals at local and global levels (IOC, 2019). Cornwell (2019) stated that sponsorships and influencer marketing connect brands with audiences through the use of relevant content. These processes aim to build brand awareness, brand equity, goodwill and other marketplace behaviours that are desirable to the brands involved (Cornwell, 2019). Sponsorship platforms also have the ability to generate emotional and cognitive responses such as attachment, love, and loyalty from their audiences (Cornwell, 2019). In this study, many participants were unable to recall Olympic sponsors or marketing content despite the fact that many Olympic sponsors post content on their social media channels. Filo et al. (2014) stated that sports consumers use social media in a variety of 
different ways and this usage can depend on their age, gender, sport context, and education. For sports sponsorship to be effective, target audiences need to be clearly identified using psychographic and demographic variables. These variables affect social media consumption, sports enthusiasm, and sponsorship support (Hazari, 2017). Sponsorship response is seen to be greater when there is an identifiable 'fit' between the sponsor and the event since it reinforces the brands' personality (Deane, 2003). Nike, Adidas, and RedBull were some of the companies that were mentioned when participants of this study were asked to recall Olympic sponsors, showing that consumers saw a natural fit between sporty brands and the Olympic Games.

Utilizing social media interactivity such as promotions, contests, and user-generated content, can enhance sponsorship effectiveness since interactivity encourages content sharing (Hazari, 2017). With regard to the Olympics, this process could be facilitated by the use of social influencers that sports fans associate with, such as famous athletes and celebrities (Hazari, 2017). Social media personalities have the ability to persuade and impact their followers using the brands' story in way that resonates with their audience; this has been found to be significantly more effective than corporate communications (Shivinski and Dabrowski, 2014; Forbes, 2016). The participants of this study confirmed that the use of social media influencers in sponsorships and marketing would be a desirable method for reaching Generation Z. Sports marketers should consider shifting their focus away from strategies that would generate traditional revenue and pay closer attention to capturing pivotal moments of culture and history. The relationship between creative execution, digital interconnectivity, and accessibility requires attention to effectively reach the Generation $\mathrm{Z}$ audience. 


\section{Implications}

\section{Theoretical Implications}

Azjen's (1991) TPB has been applied to sporting contexts in the past. However, it has seldom been applied to behaviours associated to mega-sporting events. This study provided a new direction for research using TPB in a Olympic branding context. Also, this is the first known attempt to examine Generation Z's digital Olympic experience with the use of TPB. Hence, the findings of this research have extended TPB literature and redirected it to a new context. Extant studies on the Olympic Games have focused on topics such as ambush marketing (Seguin and O'Reilly, 2008), framing (Zaharopoulous, 2004), Olympic values (Koenigstorfer and Preuss, 2018), social media (Liu, 2019), commercialization (Tomlinson, 2005) and entertainment value (Brown et al., 2019) but the findings of this study use existing literature to inform variables associated to consumer behaviour (attitudes, subjective norms and perceived behavioural control) and the Olympic brand in a new light. While Seguin et al.'s (2008) study provided some insightful results on the Olympic brand and consumer perceptions, the rapidly changing sport landscape has rendered this study somewhat dated. The results of the present study provide empirical evidence on Generation Z's current thoughts, ideas, and attitudes as they relate to the Olympic brand during a pressing time for the IOC. Additionally, while there exist many studies on the economic, social and environmental impact of hosting the Olympic Games, this is the first known study that looks at the effect of hosting the Games in a brand awareness context.

Overall, the findings of this study contribute to noted gaps in literature surrounding Generation Z's digital experience of the Olympic brand through the application of TPB as a theoretical framework. This has led to the extension of TPB by adding additional contexts in which this framework can be used to assess consumer behaviour. 


\section{Practical Implications}

While the crux of this study was exploratory in nature, several noteworthy practical implications emerged from the results. We know that generational differences occur due to changing cultural practises, social norms, and societal values over a certain period of time (Schroth, 2019). This produces new patterns of behaviour that brand managers and decision makers need to recognize. Due to its longstanding legacy, the Olympic logo has become one of the most recognizable symbols in the world (Seguin et al., 2008). Respondents of Seguin et al.'s (2008) study stated that the Olympic rings were associated to high-standards, success, world peace, and a continuous tradition of excellence. Undoubtedly, the power of the Olympic brand is recognized by the public, however, advancements in technology, the current political climate, and the unique characteristics of Generation $\mathrm{Z}$ have changed market parameters and consumer perspectives. The findings from this research serve to inform current marketing initiatives related to the Olympic brand in an effort to improve its relationship with Generation $\mathrm{Z}$, and by extension, the long-term viability of the brand.

With a plethora of readily available entertainment options to choose from, marketers have struggled to capture the interest and attention spans of Generation Z (Forbes, 2018). This was evident in the results of this study as most participants were unaware and uninterested in the content produced by the Olympic brand. In order to increase Olympic awareness among this demographic, it would seem a strategy focused on social currency might enhance reach and serve to engage this unique generation more effectively. Netflix, YouTube, and Instagram were repeatedly mentioned as the most commonly used platforms amongst this age cohort. It is recommended that brands collaborate with famous athletes and personalities that are popular amongst the youth on these platforms. Relevant influencers such as Dwayne 'The Rock' Johnson, Kevin Hart, and Christiano Ronaldo could host contests, run campaigns, and post live 'behind the scenes' content. These celebrities were mentioned since they have a "fun" 
reputation and participants have existing connections with them. Utilizing celebrities that are trusted and loved amongst the youth could bridge the gap that currently exists between Generation $\mathrm{Z}$ and the Olympics. Examples of contests that would be of interest included winning an all-inclusive, round trip to the host city. It was also mentioned that short and fun video advertisements, similar to Super Bowl half-time advertisements, were favourable among this age group.

From a marketing perspective, the Olympic movement has a very unique value proposition since it is the leading global sporting event that hosts a wide range of traditional and non-traditional sports, in various cities around the world. This means that the brand has the potential to not only attract a variety of sports enthusiasts, but also a variety of consumers that may be interested in travel and tourism, learning about different cultures, the artistic value of sports like ice skating, different languages, or those simply looking to support their nation's team through a patriotic lens. Olympic marketers have the opportunity to use these variables to curate unique and inspiring brand messaging for global audiences to consume. To increase awareness and reach, capturing new audiences through big data and behavioural segmentation is a strategy that should be considered by the IOC. This can be done by creating, distributing and promoting content based more closely on audience interest, the benefit sought, and engagement levels. Examples include video interviews with famous Olympic athletes, stories about locals in host cities, and content surrounding Olympic CSR initiatives. Based upon this research, personalized messaging specific to differing audience segments could be highly effective in this regard.

In a similar vein, investing in the production of accessible Olympic highlights is of the utmost importance since many participants suggested that due to time constraints (and perhaps the evolution of their consumer behaviour), the only way to consume sports was through video highlights. It is pivotal that marketing strategies include conveniently accessible content on 
platforms that Generation $\mathrm{Z}$ are active on (YouTube, Twitter, Instagram) since watching highlights can lead to an increased interest in the promotion of upcoming live events (Singer, 2017). Providing options that allow consumers to easily navigate to extended segments of the highlights could also be beneficial, since respondents were open to the idea of watching long videos as long as they were of interest to them.

Additionally, the results of this study highlighted the critical need for an entertaining, engaging, and a more relatable narrative from the Olympic brand. When participants were asked for insight on the expectations surrounding Olympic content, many suggested that different forms of creative story telling would be of interest. A Netflix or YouTube documentary about athlete journeys, how the Games are planned and executed, a travel series of host cities and their respective cultures, and athlete comeback stories were all mentioned by participants as potentially relevant touchpoints. It is important to note that the Olympic movement already utilizes some of these strategies. Based upon the insights from this sample population, it does not appear current Olympic content offerings are reaching the Generation $\mathrm{Z}$ audience effectively. As such, content distribution strategies may need to be revisited. Generation Z will not seek out Olympic content - they have plenty of entertainment options available to them at the click of a button and as this research suggests, their general awareness is low. Content, therefore, needs to be presented to them in the media spaces where they are already active.

The creation of drama and rivalries was mentioned as a method for generating more engagement and interest amongst audiences. Examples of rivalries between NBA teams and UFC fighters were used as reference amongst participants. The IOC values international cooperation and harmony and this makes the concept of rivalries difficult to narrate. However, light-hearted expressions of competition might be used by Olympians on their social media platforms to generate online buzz and excitement. NOC's could also encourage local sponsors 
to promote events that have international top talent competing with their respective home athletes. Canada vs. US is seen to be an existing rivalry amongst sports fans and ice hockey is a great example of a sport that both countries are passionate about. Olympic marketers should explore additional rivalries within the sports landscape and use them to promote Olympic events.

Since participation at the Olympic Games is considered to be the pinnacle of an athlete's sporting career, many audiences admire the achievements and talents of those who qualify. Olympic consumption habits amongst this age group consisted of the obvious support for an individual's home country or support for talented athletes. Usain Bolt, however, was repeatedly mentioned as a remarkable Olympian even though no participants supported Team Jamaica specifically. This indicates that Olympic broadcasters and sponsors might consider increasing the media exposure of particularly successful Olympians as opposed to merely focusing on home nation athletes and their performances. Angelini et al. (2017) mentioned that Norway's Marit Bjørgen won five medals at the Vancouver Games for cross-country skiing, yet she was the 75 th most mentioned athlete on $\mathrm{CBC}$. The top twenty athletes that were mentioned by CBC during the 2010 Games were all Canadian (Angelini et al., 2017). Team Norway won thirty-nine medals during the Pyeongchang 2018 Winter Olympics; the most a single country has ever won in Winter Olympic history. Yet, their success went mostly unnoticed in North America due to the framing of the media.

International unity was mentioned as an important concept that needs to be addressed by the Olympic movement. Although the Games are known to be inherently patriotic, there seems to be a growing need for narratives surrounding global unity and internationalism. Gottfriend and Shearer (2016) stated that the 18-29-year-old demographic relies heavily on Instagram as their news source. This provides the IOC with a unique opportunity to portray its global nature on social media, and perhaps restore the grandiosity of the Games among younger 
audiences. Athletic achievements of exceptional athletes, regardless of their national associations, need to be acknowledged and celebrated on social media. It is recommended that NOC's and local sponsors focus on promoting notions of national pride to local audiences and larger stakeholders such as official broadcasters and TOP's incorporate narratives surrounding internationalism and unity within their content strategies.

Braunstein and Ross (2010) asserted that although branding is an integral part of the marketing and communications process, it is only productive when audiences accept and endorse the developed brand. The Olympic movement greatly values excellence, respect, fairness and hope (IOC, 2020). However, with reoccurring stories of social, environmental, and economic concerns in the media, there seems to be a lack of trust surrounding Olympic ideals and consequently, the Olympic brand. With 204 NOC's, various summer and winter sports federations, global sponsors, broadcasters, and commercial partners, there are vast communication challenges that exist for the Olympic brand. What's certain is that there needs to be a clearer definition of what the Olympic movement is, what makes it unique, and why the Games matter, particularly as these questions relate to the next generation of fans. Participants of this study mentioned that transparency should be an integral part of all brands in the marketplace since transparency builds trust. Olympic marketers could benefit from making the brand more open and 'human'. Increased openness, humility and transparency through informal brand communications on digital platforms could educate audiences on current Olympic challenges, how they arose, and how the IOC continues to deal with them. This could be done through podcasts with Olympic decision makers or as mentioned above, through a docuseries on YouTube or Netflix. Leveraging influencers could also be a way to insert these discussions into Generation $\mathrm{Z}$ echo chambers. Humanizing the brand's personality and increasing transparency might allow consumers to associate relatable human attributes to the Olympic brand (Casalova and Petrakova, 2011), something that appears to be lacking in light 
of this research. Increased trust could encourage the formation of a deeper relationship between the Olympic brand and consumers (Casalova and Petrakova, 2011).

Moreover, consumer response to sponsorship activities is stronger when there is a perceived fit between the event and the sponsor (Speed and Thompson, 2000). Participant familiarity with Olympic sponsors was negligible. However, 'active' brands such as Nike, Redbull, and Gatorade were briefly mentioned. Although these responses were inaccurate, they showed natural associations made by respondents when asked to deliberate over sponsors of the Olympic event. Marketers and brand managers hope that sponsorship activities will raise brand awareness, improve engagement, and build upon the existing brand image through transferred associations (Santomier, 2008). However, with little to no recall of Olympic sponsors, it can be assumed that sponsorship activities are not reaching this age cohort effectively. Generation $\mathrm{Z}$ does not give thought to brands that make no effort to form relationships with them; they expect brands and retailers to be loyal to them (Beall, 2016). Corporations like Alibaba and Atos barely have a social media presence, let alone a relationship with Generation Z. This study illuminated the critical need for a greater sponsorship fits between the Games and their official sponsors. Remedies for this disadvantage most obviously include partnering with brands that are popular amongst Generation Z, but still relevant to the Olympic ideals. Interbrand's (2019) report on Generation Z and global brands showed the popularity of Uber, Nintendo, Netflix, Spotify, and Apple. Sponsorship activations that resonate with audiences build trust and allow the brand to transcend the event itself which can help protect the brand against negative reports and headlines (Seguin et al., 2008). In the case of the Olympics, this plays an important role in keeping the brand relevant beyond the sixteen days, every two years. The IOC might also explore the possibility of entering the eSport space since this gaming sector is growing exponentially amongst Generation Z (Tran, 2018). It is predicted that by 2023, 600 million global consumers will watch eSports and consequently, 
sponsorship revenue will increase by over $50 \%$ year after year (Tran, 2018). To benefit from this booming sector and its attractive demographics, the IOC might consider licensing its brand to a suitable eSports partner or even initiating its own gaming league, hosted in between the Summer and Winter Games. By doing so, the Olympic brand can preserve its ethos and values, while tapping into a new, sought-after market. This could help the brand maintain its relevancy during non-Olympic years as well.

Finally, the results of this research suggest that childhood exposure to sports could be an important element to consider when examining Olympic interest. This finding underscores the importance of the IOC continuing to find methods that might inspire youth to get more involved with sports within their local communities and engaging them during Olympics cycles. Sponsoring small sports teams at institutions such as high-schools, universities, or community centres might be a way to increase student awareness and involvement with the Olympic brand. This could build goodwill and act as an alternative form of advertising as well. Individual NOC's could take responsibility for these pursuits to localise their impact. Refocusing the Olympic brand's efforts towards understanding Generation Z's interests and aligning content around things that resonate with them could provide the ingredients necessary to make the Olympic brand more relevant among their next generation of fans. 


\section{Conclusions}

As Olympic audiences continue to evolve, the need for Olympic marketers and decision makers to adapt to current market trends is becoming increasingly crucial. The popularity of social media networks highlights the importance for brands to evaluate where their audience is, what they are talking about, and how they can become a part of this conversation if they are to utilize the strength of social channels effectively (Radenovic, 2013). Generation $\mathrm{Z}$ is unlike any other generation that came before them; they believe in a higher purpose and expect their favourite brands to be a part of this purpose (Interbrands, 2019). Some of the most popular brands amongst this age cohort, such as Nike, have taken public stands for the things that they believe in. Brands like Spotify and Wendy's make life more convenient and participate in popculture commentary. The Olympic brand needs to develop similar methods that would allow it to become a part of Generation Z's lives. A closer look at what resonates with this generation is pivotal for the Olympics to remain sustainable in the future. Being a likeable global brand requires reaching desirable audiences and meeting their needs effectively (Interbrands, 2019). Utilizing trustworthy and authentic influencers can bridge the existing gap between potential audiences and the Olympic brand. The movement needs to revaluate their relationships with current sponsors and reconsider what brands are offering to their consumers, as opposed to what brands are receiving as a result of an Olympic sponsorship. Being mindful of the changing media landscape alongside consumer needs, expectations, and values will contribute towards the long-term health of the Olympic movement and its ultimate long-term sustainability.

\section{Limitations}

As with all studies, limitations are identified in the design of this research project. Firstly, due to resource limitations and time constraints, the sample size of this study consisted of 22 students from a large Canadian University and thus the results are not generalizable to a global population. On the same note, although the sample consisted of participants that are 
considered to be members of Generation Z, they were business school majors pursing higher education at a prominent educational institution. Therefore, their opinions may vary from members of differing socio-economic backgrounds. In the future, a mixed-methods, more globally representative approach could be adopted to ensure the results are more generalizable to an international audience. Additionally, the nature of focus groups can unintentionally lead to a 'group think' effect that causes participants to conform to each other's opinions. This was mitigated by ensuring that the moderator was well-trained and by creating a discussion guide that helped to facilitate conversations. Lastly, due to time constraints, not all variables that could have affected Olympic awareness, perception, and engagement were explored (i.e. brand trust).

\section{Recommendations for Future Research}

This study was the first known attempt to explore Generation $\mathrm{Z}$ and their digital Olympic brand experience. Specifically, this study examined the role of TPB in determining consumer intentions and behaviour. While this study provides a good initial understanding of Generation Z's relationship with the Olympic brand, more academic inquiries are needed to explore areas that could be related to this topic. Future research may look at other international sporting events in order to document how they compare to the Olympic brand and Generation Z engagement.

Additionally, more research into athlete branding and its subsequent effect on consumer connections with Generation $\mathrm{Z}$ could be of interest to this area of study. Brand trust was a variable that was not investigated in this study. Hence, the effect of brand trust on Generation Z's consumer behaviour could be explored further. Since social media plays such a vital role for digital brand experiences, a content analysis of all Olympic social media platforms could be done to evaluate content presentation strategies and ensuing engagement levels. This could assist in optimizing social media marketing strategies moving forward. From a managerial 
perspective, the profound impact of the news media and citizen journalism on Olympic perception could be explored further. It is certain that consumer perspectives and expectations will continue to evolve over time. For the longevity of the Olympic Games, it could be beneficial to explore how different Olympic audiences can be segmented and understood based upon geographic and psychosocial variables. There is an abundance of big data that could be used to illuminate future trends and make the Olympic brand more sustainable for generations to come. 


\section{Appendix}

Discussion Guide

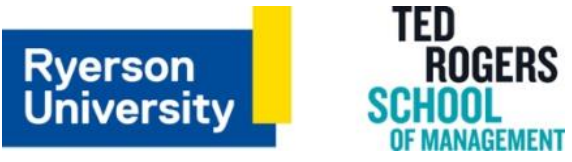

\section{"Who cares about the Olympics anyway?" - An exploratory study of Generation $Z$ and the Olympic brand experience.}

\section{Focus Group Discussion Guide}

Preamble (5 min)

- Thank and welcome

- There are no right or wrong answers

- Welcome to decline to answer any questions

- Address consent form and any questions on consent.

- Audiovisual recording and transcription

- Note that the audiovisual recording has begun.

- Going to be talking about Olympic Marketing and Branding

- Questions or concerns?

Intros and Warm-up (5 min)

- Please go around the table and introduce yourself

- Do you watch or play any sports? If yes, which ones?

- Did you grow up in a household that enjoyed watching sporting events?

Sports Consumption Habits (5 min)

- What is your preferred method of viewing sports and why? Do you have a cable subscription?

- Where do you get your sports information/insights from?

- How do you feel about viewing sports on social media platforms such as Facebook, YouTube, Instagram and Twitter?

- Do you follow your favorite athletes or sports teams on social media?

- How do you consume Olympic sport content?

Olympic Games Awareness \& Attitudes (10 min)

- Do you know when and where the next Olympics are being hosted?

- What is the first thing that comes to your mind when you think of the Olympic Games?

- What is your favorite Olympic memory?

- Do you follow the performance of a specific country or specific sports/athletes?

- Do you have any favorite Olympic athletes?

- Can you name any Olympic sponsors off the top of your head?

Olympic Brand (20 min)

- What qualities would make you follow a brand on social media?

- How do you like to engage with brands on social media?

- Have you seen any Olympic content on your social media?

- What is your experience accessing Olympic broadcasts or other Olympic content?

Subjective Norms (10 min)

- Have you ever gone out to watch sports just because your friends and family were going?

- Have you ever encouraged your friends or family to follow Olympic sports/athletes? 
- Would you consider watching more of the Olympics if your friends and family encouraged you to do so?

- Do you have any recommendations on how to enhance your engagement with the Olympic brand?

Closing (5 min)

- Thank for time

- Final thought's you'd like to share?

- Questions or concerns?

- Research Results - Mention thesis defense

- Note that the audiovisual recording has ended 


\section{References}

Aaker, J. L. (1997). Dimensions of Brand Personality. Journal of Marketing Research,34(3), 347-356. doi:10.2307/3151897

Aaker, D. A. (1998). Developing business strategies: Strategic market management. New York: Wiley.

Aaker, J. L. (1999). The Malleable Self: The Role of Self-Expression in Persuasion. Journal of Marketing Research,36, 45-57. doi:10.2139/ssrn.945453

Agius, A. (2018, July 04). 5 Brands That Prove Live Video Is The Future of Content Marketing. Retrieved from https://www.jeffbullas.com/live-video-content-marketing/

Allen, E. \& Olson, J. (1995) Conceptualizing and creating brand personality: a narrative theory approach. In: F.R. Kardes \& M. Sujan (eds) Advances in Consumer Research (pp. 391-395). Provo, UT: Association for Consumer Research.

Andrews, D., \& Grainger, A. (2007). Sport and Globalization. In The Blackwell Companion to Globalization(pp. 478-497). Malden, Massachussetts: Blackwell Publishing.

Arai, A., Ko, Y. J., \& Ross, S. (2014). Branding athletes: Exploration and conceptualization of athlete brand image. Sport Management Review,17(2), 97-106.

doi:10.1016/j.smr.2013.04.003

Azjen, I. (1991). The Theory of Planned Behaviour. Organizational Behaviour and Human Decision, 50, 179-211.

Ajzen, I., \& Fishbein, M. (1980). Understanding attitudes and predicting social behavior. Englewood Cliffs, NJ: Prentice-Hall.

Barreda, A., \& Bilgihan, A. (2013). An analysis of user-generated content for hotel experiences. Journal of Hospitality and Tourism Technology,4(3), 263-280. doi:10.1108/jhtt-01-2013-0001

Barrett, J. (2018, December 20). 3 Things You Need to Know About Gen Z in 2019. Retrieved from https://www.inc.com/jeff-barrett/3-things-you-need-to-know-aboutgen-z-in-2019.html

Bassiouni, D. H., \& Hackley, C. (2014). Generation Z' children's adaptation to digital consumer culture: A critical literature review. Journal of Customer Behaviour, 13(2), 113-133.

Batty, R. J., \& Gee, S. (2019). Fast food, fizz, and funding: Balancing the scales of regional sport organisation sponsorship. Sport Management Review,22(1), 167-179. doi:10.1016/j.smr.2018.06.014

Beall, G. (2016, May 11). 8 Key Differences between Gen Z and Millennials. Retrieved from https://www.huffpost.com/entry/8-key-differences-between_b_12814200 
Bechtoldt, M. (2018, November 09). Gen Z changing the way sports are consumed. Retrieved from https://globalsportmatters.com/youth/2018/11/09/gen-z-changing-the-waysports-are-consumed/

Bessi, A., Coletto, M., Davidescu, G. A., Scala, A., Caldarelli, G., \& Quattrociocchi, W. (2015). Science vs Conspiracy: Collective Narratives in the Age of Misinformation. Plos One, 10(2). doi: 10.1371/journal.pone.0118093

Billings, A. C. (2008). Olympic media: Inside the biggest show on television. London: Routledge.

Billings, A.C. (2010). Reaction time: Assessing the record and advancing a future of sports media scholarship. In A.C. Billings (Ed.), Sports media: Transformation, integration, consumption (pp. 181-190). New York City, New York: Routledge

Bhattacharya, C., \& Sen, S. (2003). Consumer-Company Identification: A Framework for Understanding Consumers' Relationships with Companies. Journal of Marketing,67(2), 76-88. doi:10.1509/jmkg.67.2.76.18609

Blackston, M. (2000). Observations: Building brand equity by managing the brand's Relationships. Journal of Advertising Research, 40(6), 101-105.

Bogage, J. (2019, August 28). High school sports participation drops for the first time in 30 years. Retrieved from https://www.washingtonpost.com/sports/2019/08/28/highschool-sports-participation-drops-first-time-years/

Braunstein, J.R., \& Ross, S.D. (2010). Brand personality in sport: Dimension analysis and general scale development. Sport Marketing Quarterly, 19, 8-16.

Brautigam, T. (2018, February 23). INTERVIEW: Jens Thiemer, Mercedes-Benz: "We Are Well Positioned to Support Esports in a Substantial Way". Retrieved from https://esportsobserver.com/interview-jens-thiemer-mercedes-benz/

Brown, K. A., Brown-Devlin, N., Devlin, M. B., \& Billings, A. C. (2019). The Evolution and Fragmentation of Olympic Media Consumption and Its Impact on the Entertainment Value of the 2018 Winter Olympics. Communication Research Reports,36(2), 103113. doi:10.1080/08824096.2019.1586665

Bullock, L. (2018, December 28). 5 Brands Taking Personalized Marketing To The Next Level. Retrieved from https://www.forbes.com/sites/lilachbullock/2018/12/28/5brands-taking-personalized-marketing-to-the-next-level/\#6baf3903c8ff

Carufel, R. (2018, October 25). Sports PR-how Gen Z is redefining consumption and sponsorship. Retrieved from https://www.agilitypr.com/pr-news/publicrelations/sports-pr-how-gen-z-is-redefining-consumption-and-sponsorship/

Casella, B. (2017, February 15). The World's 21 Most Recognized Brand Logos of all Time. Retrieved from https://www.impactbnd.com/blog/most-recognized-brand-logosidentities 
Čáslavová, E. \& Petráčková, J. (2011). The brand personality of large sports events. Kinesiology, 43(1), 91-106.

Chang, C. (2016). How the Olympics Lost Millennials. Retrieved from https://newrepublic.com/article/136096/olympics-lost-millennials

Chappelet, J., \& Kübler-Mabbott, B. (2008). International Olympic Committee and the Olympic system: The governance of world sport. Milton Park: Routledge.

Christensen, C. G., Bickham, D., Ross, C. S., \& Rich, M. (2015). Multitasking With Television Among Adolescents. Journal of Broadcasting \& Electronic Media,59(1), 130-148. doi:10.1080/08838151.2014.998228

Chaykowski, K. (2017, October 18). Digital Video Marketing Is A \$135 Billion Industry In The U.S. Alone, Study Finds. Retrieved from https://www.forbes.com/sites/kathleenchaykowski/2017/10/18/digital-videomarketing-is-a-135-billion-industry-in-the-u-s-alone-study-finds/\#2b4475abd4dd

Cheng, C.-F., Chen, L. H., Chen, M.-Y., \& Lu, W.-C. (2012). Fan participation behaviour in baseball: an application of the theory of planned behaviour. International Journal of Sports Marketing and Sponsorship, 14(1), 17-28. doi: 10.1108/ijsms-14-01-2012b003

Chu, S., \& Kim, Y. (2011). Determinants of consumer engagement in electronic word-ofmouth (eWOM) in social networking sites. International Journal of Advertising,30(1), 47-75. doi:10.2501/ija-30-1-047-075

Cialdini, R., Borden, R., Thorne, A., Walker, M. R., Freeman, S., \& Sloan, L. (1976). Basking in reflected glory: Three (football) field studies. Journal of Personality and Social Psychology, 34(3), 366-375. doi: 10.1037/0022-3514.34.3.366

Claveria, K. (2019, April 24). Generation Z Statistics: New Report on the Values, Attitudes, and Behaviors of the Post-Millennials. Retrieved from https://www.visioncritical.com/blog/generation-z-statistics

Clement, J. (2019, August 15). Second screen usage of teens when watching TV 2018. Retrieved from https://www.statista.com/statistics/295016/teens-tv-internet-secondscreen-usage/

Clifton, R., \& Maughan, E. (2000). The future of brands: Twenty-five visions. Basingstoke: MacMillan Press.

Cohen, G.L., \& Garcia, J. (2005). I am us: Negative stereotypes as collective threats. Journal of Personality and Social Psychology, 89(4), 566-582. doi:10.1037/00223514.89.4.566

Cornwell, T. B. (2008). State of the art and science in sponsorship-linked marketing. Journal of Advertising,37(3), 41-55. doi:10.4337/9781781005866.00035 
Cornwell, T. B. (2019). Less "Sponsorship As Advertising" and More Sponsorship-Linked Marketing As Authentic Engagement. Journal of Advertising,48(1), 49-60. doi:10.1080/00913367.2019.1588809

Cunningham, G. B., \& Kwon, H. (2003). The Theory of Planned Behaviour and Intentions to Attend a Sport Event. Sport Management Review, 6(2), 127-145. doi: 10.1016/s14413523(03)70056-4

Dave, N. (2018, July 11). Why Live Videos On Social Media Are A Game-Changer for Marketers. Retrieved from https://www.jeffbullas.com/live-videos-on-social-media/

Davies, G., Rojas-Méndez, J. I., Whelan, S., Mete, M., \& Loo, T. (2018). Brand personality: Theory and dimensionality. Journal of Product \& Brand Management,27(2), 115127. doi:10.1108/jpbm-06-2017-1499

Daymon, C., \& Holloway, I. (2011). Qualitative research methods in public relations and marketing communications. London: Routledge.

Deane, J. (2003). Sports Sponsorship and Brand Personality - The Ryder Cup Team and IBM. International Journal of Sports Marketing and Sponsorship,5(3), 21-36. doi:10.1108/ijsms-05-03-2003-b003

Donlan, L., \& Crowther, P. (2012). Leveraging sponsorship to achieve consumer relationship objectives through the creation of 'marketing spaces': An exploratory study. Journal of Marketing Communications,20(4), 291-306. doi:10.1080/13527266.2012.684068

Duffett, R. (2017). Influence of social media marketing communications on young consumers' attitudes, Young Consumers, 18(1), 19-39. https://doi.org/10.1108/YC-072016-00622

Eagleman, A. N., \& Burch, L. M. (2016). Communicating via photographs: A gendered analysis of Olympic athletes' visual self-presentation on Instagram. Sport Management Review,19(2), 133-145. doi:10.1016/j.smr.2015.03.002

Eckler, P., \& Bolls, P. (2011). Spreading the Virus: Emotional Tone of Viral Advertising and Its Effect on Forwarding Intentions and Attitudes. Journal of Interactive Advertising, 11(2), 1-11. doi: 10.1080/15252019.2011.10722180

Epstein, A. (2017). The Ambush at Rio. The John Marshall Review of Intellectual Property Law, 16(350), 351-381.

Ewah, S. O. E., Igbaji, P. M., \& Umeh, C. I. (2014). Should Marketers Try to Change Consumers Unfavourable Attitude for their Product into Favourable? International Journal of Academic Research in Business and Social Sciences, 4(10), 631-643. doi: 10.6007/ijarbss/v4-i10/1259

Faull, J. (2016, July 25). Is the Olympics a brand in trouble after contentious decision to let Russia into Rio? Retrieved from https://www.thedrum.com/news/2016/07/25/olympics-brand-trouble-aftercontentious-decision-let-russia-rio 
Filo, K., Lock, D., and Karg, A. (2015). Sport and social media research: A review. Sport Management Review, 18(2), 166-181.

Flint, C. (2018, August 7). Learn To Tap Cultural Moments As Second Screen Evolves. Retrieved from https://www.mediapost.com/publications/article/323273/learn-to-tapcultural-moments-as-second-screen-evo.html

Forbes, K. (2016). Examining the Beauty Industry's Use of Social Influencers. Elon Journal of Undergraduate Research in Communications, 7(2), 1-106.

Forbes. (2018, February 22). 13 Strategies For Marketing To Generation Z. Retrieved from https://www.forbes.com/sites/forbesbusinessdevelopmentcouncil/2018/02/22/13strategies-for-marketing-to-generation-z/\#181e14231c37

Fowler, D. (2015, October 18). The A B C of next generation sponsorship. Retrieved from https://davidgfowler.wordpress.com/2015/10/17/the-a-b-c-of-next-gen-sponsorship/

Franck, E., \& Nüesch, S. (2010). Talent And/or Popularity: What Does It Take To Be A Superstar? Economic Inquiry,50(1), 202-216. doi:10.1111/j.1465-7295.2010.00360.x

Gale, S. F. (2015, July 7). Forget Gen Y: Are You Ready for Gen Z? Retrieved from https://www.chieflearningofficer.com/2015/07/07/forget-gen-y-are-you-ready-forgen-z/

Gangadharbatla, H. (2008). Facebook Me: Collective Self-esteem, Need to Belong, and Internet Self efficacy as Predictors of the iGeneration's Attitudes Toward Social Networking Sites. Journal of Interactive Advertising, 8(2), 5-15. doi:10.1080/15252019.2008.10722138

Garcia, A. (2018, February 17). Why sponsors are breaking up with the Olympics. Retrieved from https://money.cnn.com/2018/02/17/news/companies/olympic-sponsorsmcdonalds-budweiser/index.html

Gillett, R. (2014, December 7). How the most successful brands dominate Instagram, and you can too. Retrieved from http://www.fastcompany.com/3029395/bottom-line/ how-themost-successful-brands-dominate-instagram-and-you-can-too

Gill, P., Stewart, K., Treasure, E., \& Chadwick, B. (2008). Methods of data collection in qualitative research: interviews and focus groups. British Dental Journal, 204(6), 291-295. doi: 10.1038/bdj.2008.192

Giorgio, P. (2019, July 4). Integrating Venue Technology Into Sports Business to Enhance Fan Experience. Retrieved from https://www2.deloitte.com/us/en/pages/consumerbusiness/articles/integrating-venue-technology-sports-business.html

Goby, V. P. (2006). Online Purchases in an Infocomm Sophisticated Society. CyberPsychology \& Behavior, 9(4), 423-431. doi: 10.1089/cpb.2006.9.423 
Google. (2018). Sports fans take fandom to new levels with online video . Retrieved from https://www.thinkwithgoogle.com/consumer-insights/sports-fans-video-insights/

Gottfried, F. \& Shearer, E. (2016). News use across social media platforms 2016.

Retrieved from http://journalism.org/2016/05/26/news-use-across-social-media-platforms2016.

Grohmann, K., \& Baker, L. (2018, February 18). Tarnished? Olympic brand mints money like never before. Retrieved from https://www.reuters.com/article/us-olympics-2018ioc-asia-analysis/tarnished-olympic-brand-mints-money-like-never-beforeidUSKCN1G20DH

Grow, J. M., \& Yang, S. (2018). Generation-Z Enters the Advertising Workplace: Expectations Through a Gendered Lens. Journal of Advertising Education,22(1), 722. doi:10.1177/1098048218768595

Guichard, B. (2019, February 01). Is Broadcasting Sports Direct-to-Consumer A Savvy Business? Retrieved from https://cleeng.com/blog/broadcasting-sports-direct-toconsumer-savvy-business-model\#gs.q1pgso

Gupta, S., \& Wright, O. (2019, February 07). How Global Brands Can Respond to Local Competitors. Retrieved from https://hbr.org/2019/02/how-global-brands-can-respondto-local-competitors

Guo, M., \& Chan-Olmsted, S. M. (2015). Predictors of Social Television Viewing: How Perceived Program, Media, and Audience Characteristics Affect Social Engagement With Television Programming. Journal of Broadcasting \& Electronic Media,59(2), 240-258. doi:10.1080/08838151.2015.1029122

Hazari, S. (2018). Investigating social media consumption, sports enthusiasm, and gender on sponsorship outcomes in the context of Rio Olympics. International Journal of Sports Marketing and Sponsorship, 19(4), 396-414. doi: 10.1108/ijsms-01-2017-0007

Hegner, S. M., Fenko, A., \& Teravest, A. (2017). Using the theory of planned behaviour to understand brand love. Journal of Product \& Brand Management, 26(1), 26-41. doi: 10.1108/jpbm-06-2016-1215

Hodge, C., \& Walker, M. (2015). Personal branding: A perspective from the professional athlete-level-of-analysis. International Journal of Sport Management and Marketing, 16(1/2), 112-131. doi:10.1504/ijsmm.2015.074920

Holt, D., Quelch, J. and Taylor, E. (2003). Managing the Transnational Brand: How Global Perceptions Drive Value. Boston: Harvard Business School.

Hsu, M.-H., Yen, C.-H., Chiu, C.-M., \& Chang, C.-M. (2006). A longitudinal investigation of continued online shopping behavior: An extension of the theory of planned behavior. International Journal of Human-Computer Studies, 64(9), 889-904. doi: 10.1016/j.ijhcs.2006.04.004 
Interbrand. (2019). How the Best Global Brands Connect with Gen Z. Retrieved from https://www.interbrand.com/best-brands/best-global-brands/2019/articles/how-thebest-global-brands-connect-with-gen-zl

International Olympic Committee. (2013, February 12). The Olympic brand maintains its global strength and recognition. Retrieved from https://www.olympic.org/news/the-olympicbrand-maintains-its-global-strength-and-recognition

International Olympic Committee. (1997) Olympic Marketing Research Analysis Report, International Olympic Committee, Lausanne, Switzerland.

International Olympic Committee. (2014). The Youth Olympic Games Vision and Principles. Retrieved from

http://www.olympic.org/Documents/Reference_documents_Factsheets/The_Youth_O lympic_Games.pdf

International Olympic Committee. (2019). Olympic marketing fact file: 2019 edition.

Retrieved from:

https://www.olympic.org/en/Home/Documents/Documents/IOC\%20Marketing\%20an d\%20Broadcasting/IOC\%20Marketing\%20and\%20Broadcasting/01\%20\%200lympic\%20Marketing\%20Fact\%20File/Olympic\%20Marketing\%20Fact\%20Fil e\%202018

International Olympic Committee. (2020). Who We Are. Retrieved from: https://www.olympic.org/about-ioc-olympic-movement

Jones, M. (2019, February 14). As Industry Grows, Percentage of U.S. Sports Fans Steady. Retrieved from https://news.gallup.com/poll/183689/industry-grows-percentagesports-fans-steady.aspx

Kang, M., Shin, D., \& Gong, T. (2016). The role of personalization, engagement, and trust in online communities. Information Technology \& People,29(3), 580-596. doi:10.1108/itp-01-2015-0023

Kapferer, J. N. (2008). The New Strategic Brand Management: Creating and sustaining brand equity long term (4th ed.). London: Kogan Page.

Keller, K. L. (1993). Conceptualizing, Measuring, and Managing Customer-Based Brand Equity. Journal of Marketing,57(1), 1. doi:10.2307/1252054

Kenyon, J. A., Manoli, A. E., \& Bodet, G. (2018). Brand consistency and coherency at the London 2012 Olympic Games. Journal of Strategic Marketing,26(1), 6-18. doi:10.1080/0965254x.2017.1293139

Killian, G., \& Mcmanus, K. (2015). A marketing communications approach for the digital era: Managerial guidelines for social media integration. Business Horizons,58(5), 539-549. doi:10.1016/j.bushor.2015.05.006 
Kim, M. S., \& James, J. (2016). The theory of planned behaviour and intention of purchase sport team licensed merchandise. Sport, Business and Management: An International Journal, 6(2), 228-243. doi: 10.1108/sbm-02-2014-0005

Kim, Y., Yim, K., \& Ko, Y. J. (2013). Consumer patriotism and response to patriotic advertising: comparison of international vs. national sport events. International Journal of Sports Marketing and Sponsorship, 14(3), 74-96. doi: 10.1108/ijsms-1403-2013-b006

Kitzinger, J. (1994). The methodology of Focus Groups: the importance of interaction between research participants. Sociology of Health and Illness, 16(1), 103-121. doi: 10.1111/1467-9566.ep11347023

Koenigstorfer, J., \& Preuss, H. (2018). Perceived Values in relation to the Olympic Games: Development and use of the Olympic Value Scale. European Sport Management Quarterly,18(5), 607-632. doi:10.1080/16184742.2018.1446995

Kohe, G. Z. (2016). London 2012 (Re)calling: Youth memories and Olympic 'legacy' ether in the hinterland. International Review for the Sociology of Sport, 52(1), 24-44. doi: $10.1177 / 1012690215581604$

Krieger, J. (2012). Fastest, highest, youngest? Analysing the athlete's experience of the Singapore Youth Olympic Games. International Review for the Sociology of Sport,48(6), 706-719. doi:10.1177/1012690212451875

Krueger, R. A. (1994). Focus groups: a practical guide for applied research. Thousand Oaks, CA: SAGE.

Krueger, R. A., \& Casey, M. A. (2015). Focus groups: a practical guide for applied research. Los Angeles: SAGE.

Lam, S. K., Ahearne, M., Hu, Y., \& Schillewaert, N. (2010). Resistance to Brand Switching When a Radically New Brand Is Introduced: A Social Identity Theory Perspective. Journal of Marketing, 74(6), 128-146. doi:10.1509/jmkg.74.6.128

Lee, J. (2005). Marketing and Promotion of the Olympic Games. The Sport Journal, 8(3), 111.

Lee, H., \& Cho, C. (2009). The Matching Effect of Brand and Sporting Event Personality: Sponsorship Implications. Journal of Sport Management,23(1), 41-64. doi:10.1123/jsm.23.1.41

Lee, C. S., \& Ma, L. (2012). News sharing in social media: The effect of gratifications and prior experience. Computers in Human Behavior, 28(2), 331-339. doi: 10.1016/j.chb.2011.10.002

Li, Y., \& Lin, G. (2012). Exploring the extrinsic and intrinsic motivations in blogging: Results of a survey of Hong Kong University Students. Online Journal of Communication and Media Technologies, 1(4), 54-63. 
Liang, T., Chen, H., \& Turban, E. (2009). Effect of personalization on the perceived usefulness of online customer services. Journal of Electronic Commerce Research,13(4), 275-288. doi:10.1145/1593254.1593296

Littleton, J. (2018, February 20). Spending Habits Of Gen Z: They Like To Own Stuff. Retrieved from https://www.mediapost.com/publications/article/314842/spendinghabits-of-gen-z-they-like-to-own-stuff.html

Liu, Y. (2019). The Development of Social Media and its Impact on the Intercultural Exchange of the Olympic Movement, 2004-2012. Olympics in Conflict, 93-108. doi: $10.4324 / 9781351181488-7$

Lobaugh, K., Stephens, B., \& Simpson, J. (2019, May 29). The consumer is changing, but perhaps not how you think. Retrieved from https://www2.deloitte.com/us/en/insights/industry/retail-distribution/the-consumer-ischanging.html

Loveland, E. (2017). Instant Generation. The Journal of College Admission, (234), 34-38.

Maehle, N., \& Supphellen, M. (2011). In Search of the Sources of Brand Personality. International Journal of Market Research,53(1), 95-114. doi:10.2501/ijmr-53-1-095-114

Maguire, J., Barnard, S., Butler, K., \& Golding, P. (2008). Olympic Legacies in the IOCs 'Celebrate Humanity' Campaign: Ancient or Modern? The International Journal of the History of Sport, 25(14), 2041-2059. doi:10.1080/09523360802439239

Maguire, J., \& Tuck, J. (1998). Global sports and patriot games: Rugby union and national identity in a united sporting kingdom since 1945. Immigrants \& Minorities, 17(1), 103-126. doi: 10.1080/02619288.1998.9974931

Malär, L., Krohmer, H., Hoyer, W. D., \& Nyffenegger, B. (2011). Emotional Brand Attachment and Brand Personality: The Relative Importance of the Actual and the Ideal Self. Journal of Marketing, 75(4), 35-52. doi:10.1509/jmkg.75.4.35

Malfas, M., Theodoraki, E., \& Houlihan, B. (2004). Impacts of the Olympic Games as megaevents. Municipal Engineer,157(3), 209-220. doi:10.1680/muen.157.3.209.49461

Mangold, W. G., \& Faulds, D. J. (2009). Social media: The new hybrid element of the promotion mix. Business Horizons,52(4), 357-365. doi:10.1016/j.bushor.2009.03.002

Marshall, P. D., Walker, B., \& Russo, N. (2010). Mediating the Olympics. Convergence: The International Journal of Research into New Media Technologies, 16(3), 263-278. doi: $10.1177 / 1354856510367619$

Matrix, S. (2014). The Netflix Effect: Teens, Binge Watching, and On-Demand Digital Media Trends. Jeunesse: Young People, Texts, Cultures, 6(1), 119-138. doi: 10.1353/jeu.2014.0002 
Mcallister, M. P., \& Turow, J. (2002). New Media and the Commercial Sphere: Two Intersecting Trends, Five Categories of Concern. Journal of Broadcasting \& Electronic Media,46(4), 505-514. doi:10.1207/s15506878jobem4604_1

Meenaghan, T., \& Osullivan, P. (2001). Editorial: The passionate embrace-consumer response to sponsorship. Psychology and Marketing, 18(2), 87-94. doi:10.1002/15206793(200102)18:23.3.co;2-c

Mocanu, D., Rossi, L., Zhang, Q., Karsai, M., \& Quattrociocchi, W. (2015). Collective attention in the age of (mis)information. Computers in Human Behavior, 51, 11981204. doi: 10.1016/j.chb.2015.01.024

Molla, R. (2018, February 9). Olympics viewership is down, even as NBC pays more for the rights to air it. Retrieved from https://www.vox.com/2018/2/9/16975680/olympicswinter-2018-viewership-down-nbc-rights-pyeongchang

Mulcahy, G. (2019, August 14). Why Sports Participation in Canada is Declining. Retrieved from https://www.paradigmsports.ca/sports-participation-canada-declining/

Muntinga, D. G., Smit, E., \& Moorman, M. (2012). Social Media DNA: How Brand Characteristics Shape COBRAs. Advances in Advertising Research,3(1), 121-135. doi:10.1007/978-3-8349-4291-3_10

Nee, R. C. (2015). Gatekeeping the 2012 Olympic Games. Journalism \& Mass Communication Quarterly,92(1), 77-98. doi:10.1177/1077699014560517

Nickisch, C. (2016, August 05). The Olympics Needs a New Business Model. Retrieved from https://hbr.org/2016/08/the-olympics-needs-a-new-business-model

Nielsen (2018). Top 5 Global Sports Industry Trends. Retrieved from http://nielsensports.com/wp-content/uploads/2014/09/nielsen-top-5-commercialsports-trends-2018.pdf

Nielsen. (2018, November 6). Disruption Opportunity For Sports Consumption In A Changing Media Landscape. Retrieved from https://www.nielsen.com/za/en/pressreleases/2018/disruption-opportunity-for-sports-consumption-in-a-changing-medialandscape/

Nowak, L., Thach, L., \& Olsen, J. E. (2006). Wowing the millennials: Creating brand equity in the wine industry. Journal of Product \& Brand Management, 15(5), 316-323. doi:10.1108/10610420610685712

O'Brien, N. (2019, May 17). Gen Z Has Arrived, It's Time You Get to Know Them. Retrieved from https://www.linkedin.com/pulse/gen-z-has-arrived-its-time-you-getknow-them-natalie-o-brien-am/

Omona, J. (2013). Sampling in Qualitative Research: Improving the Quality of Research Outcomes in Higher Education. Makerere Journal of Higher Education, 4(2). doi: 10.4314/majohe.v4i2.4 
Parganas, P., Anagnostopoulos, C., \& Chadwick, S. (2015). 'You'll never tweet alone': Managing sports brands through social media. Journal of Brand Management, 22(7), 551-568. doi: 10.1057/bm.2015.32

Pegoraro, A., \& Jinnah, N. (2012). Tweet 'em and reap 'em: The impact of professional athletes use of twitter on current and potential sponsorship opportunities. Journal of Brand Strategy, 1(1), 85-97.

Park, J., Sung, J., Son, J., Na, K., \& Kim, S. (2019). Athletes' brand equity, spectator satisfaction, and behavioral intentions. Asia Pacific Journal of Marketing and Logistics,31(2), 541-558. doi:10.1108/apjml-05-2018-0176

Patel, D. (2018, December 31). 10 Social Media Trends to Watch in 2019. Retrieved from https://www.entrepreneur.com/article/324901

Parmentier, M.A. and Fischer, E. (2012). How athletes build their brands. International Journal of Sport Management and Marketing, 11(1), 106-124.

Pedersen, P. M. (2014). A Commentary on Social Media Research From the Perspective of a Sport Communication Journal Editor. Communication \& Sport, 2(2), 138-142. https://doi.org/10.1177/2167479514527428

Pentony, L. (2016, August 4). IOC defends new Olympic sports as it reaches out to youth. Retrieved from https://www.abc.net.au/news/2016-08-05/ioc-defends-new-olympicsports-as-it-reaches-out-to-youth/7692822

Petersen, J., Deitz, S., Bellar, D and Judge, L. (2015). Youth Olympic Games Awareness: An Analysis of Parents of Elite Youth Sport Athletes. Global Sport Business Journal, $3(3), 29-41$.

Pfahl, M. E., Kreutzer, A., Maleski, M., Lillibridge, J., \& Ryznar, J. (2012). If you build it, will they come?: A case study of digital spaces and brand in the National Basketball Association. Sport Management Review, 15(4), 518-537. doi:10.1016/j.smr.2012.03.004

Pfanner, E. (2012, July 01). Social Media Is the Message for Olympics. Retrieved from https://www.nytimes.com/2012/07/02/technology/social-media-is-the-message-forolympics.html?_r=0

Pfeffel, F., Kexel, P., Kexel, C. A., \& Ratz, M. (2016). Second Screen: User Behaviour of Spectators while Watching Football. Athens Journal of Sports,3(2), 119-128. doi:10.30958/ajspo.3-2-2

Pickett, L., Ginsburg, J., Mendez, V., Lim, E., Blankenship, R., Foster, E., Lewis, H., Ramon, W., Saltis, M. and Sheffield, B. (2012). Ajzen's Theory of Planned Behavior as it Relates to Eating Disorders and Body Satisfaction. North American Journal of Psychology, 14(2), 339-354 
Poe, J. (2019, Apr 04). Poe's perspective: Generation Z represents crucial sports audience. Retrieved from http://ezproxy.lib.ryerson.ca/login?url=https://search-proquestcom.ezproxy.lib.ryerson.ca/docview/2202731008?accountid=13631

Preuss, H. (2002). Economic Dimension of the Olympic Games. Lecture presented at Centre D’Estudis Olímpics in University of Cologne, Barcelona.

Priporas, C., Stylos, N., \& Fotiadis, A. K. (2017). Generation Z consumers expectations of interactions in smart retailing: A future agenda. Computers in Human Behavior,77, 374-381. doi:10.1016/j.chb.2017.01.058

Radenovic, N. (2013, January 19). How the NBA Encourages Social Media Participation. Retrieved from https://nrdigitalbranding.com/blog/how-the-nba-encourages-socialmedia-participation/

Rapoza, K. (2019, June 11). Global Esports Popularity Give Gamer Companies Reason To Be Bullish. Retrieved from https://www.forbes.com/sites/kenrapoza/2019/05/29/global-esports-popularity-givegamer-companies-reason-to-be-bullish/\#56e0cc851bde

Razvan, B and Catalin, P. (2018). Branding in Sport. Annals of the of the University of Craiova: Economic Sciences Series. 2(46). 35-41.

Ritchie, J., \& Spencer, L. (1994). Qualitative data analysis for applied policy research. In Analysing qualitative data (pp. 173-194). London: Routledge.

Rivers, A. (2016, August 15). How Rule 40 Affects the Olympic Marketing Efforts of Smaller Brands. Retrieved from https://www.themarketingscope.com/how-rule-40affects-the-olympic-marketing-efforts-of-smaller-brands/

Robles, P. (2018, February 7). How sports advertisers should react to changing media consumption. Retrieved from https://econsultancy.com/how-sports-advertisersshould-react-to-changing-media-consumption/

Sánchez-Miguel, P. A., Leo, F. M., Sánchez-Oliva, D., Amado, D., \& García-Calvo, T. (2013). The Importance of Parents' Behavior in their Children's Enjoyment and Amotivation in Sports. Journal of Human Kinetics, 36(1), 169-177. doi: 10.2478/hukin-2013-0017

Santomier, J. (2008). New media, branding and global sports sponsorship. International Journal of Sports Marketing and Sponsorship, 10(1), 9-22. doi:10.1108/ijsms-10-012008-b005

Saunders, B., Sim, J., Kingstone, T., Baker, S., Waterfield, J., Bartlam, B., ... Jinks, C. (2017). Saturation in qualitative research: exploring its conceptualization and operationalization. Quality \& Quantity, 52(4), 1893-1907. doi: 10.1007/s11135-0170574-8

Saxena, S. (2019). Generation ' $Z$ '- The segment of contest for marketers. Advances in Managements, 12(2), 15-15. 
Scandizzo, P. L., \& Pierleoni, M. R. (2017). Assessing The Olympic Games: The Economic Impact And Beyond. Journal of Economic Surveys, 32(3), 649-682. doi: 10.1111/joes. 12213

Schivinski, B., \& Dabrowski, D. (2014). The effect of social media communication on consumer perceptions of brands. Journal of Marketing Communications, 22(2), 189214. doi: 10.1080/13527266.2013.871323

Schmid, B., Kexel, C. \& Djafarova, E. (2016). Multidimensional Sports Spectators Segmentation and Social Media Marketing. International Scholarly and Scientific Research \& Innovation, 10(8), 2657-2660. doi: 10.5281/zenodo.1125860

Schomer, A. (2019, January 18). News and sports OTT services threaten to further erode payTV. Retrieved from https://www.businessinsider.com/live-news-sports-ott-servicesthreaten-pay-tv-2019-1

Schroth, H. (2019). Are You Ready for Gen Z in the Workplace? California Management Review,61(3), 5-18. doi:10.1177/0008125619841006

Schuiling, I., \& Kapferer, J. (2004). Executive Insights: Real Differences between Local and International Brands: Strategic Implications for International Marketers. Journal of International Marketing, 12(4), 97-112. doi:10.1509/jimk.12.4.97.53217

Seguin, B., Richelieu, A., \& Oreilly, N. (2008). Leveraging the Olympic brand through the reconciliation of corporate and consumers brand perceptions. International Journal of Sport Management and Marketing,3(1/2), 3-22. doi:10.1504/ijsmm.2008.015958

Seno, D., \& Lukas, B. A. (2007). The equity effect of product endorsement by celebrities. European Journal of Marketing,41(1/2), 121-134. doi:10.1108/03090560710718148

Shank, M. D. (1999). Sports marketing: A strategic perspective (2nd ed.). New Jersey: Prentice Hall.

Shoval, N. (2002). A new phase in the competition for the Olympic Gold: the London and New York Bids for the 2012. Games. Journal of Urban Affairs, 24(5): 583-599. doi:10.1111/1467-9906.00146

Singer, D. (2017, October). We are wrong about millennial sports fans. Retrieved from https://www.mckinsey.com/industries/technology-media-andtelecommunications/our-insights/we-are-wrong-about-millennial-sports-fans

Slater, A., \& Tiggemann, M. (2010). "Uncool to do sport": A focus group study of adolescent girls' reasons for withdrawing from physical activity. Psychology of Sport and Exercise, 11(6), 619-626. doi: 10.1016/j.psychsport.2010.07.006

Slater, M. (2009). Youthful Outlook, Olympic Review, 71, 26-49. 
Smith, L. R., \& Smith, K. D. (2012). Identity in Twitter's Hashtag Culture: A Sport-MediaConsumption Case Study. International Journal of Sport Communication,5(4), 539557. doi:10.4135/9781526437570

Sparks, P., Guthrie, C.A. and Shepherd, R. (1997), The dimensional structure of the perceived behavioural construct. Journal of Applied Social Psychology, 27(5), 418438.

Special, R. L. (1979, September 27). ABC-TV Pays Record 225 Million for '84 Olympics. Retrieved from https://www.nytimes.com/1979/09/27/archives/abctv-pays-record225-million-for-84-olympics-rise-in-advertising.html

Speed, R., \& Thompson, P. (2000). Determinants of Sports Sponsorship Response. Journal of the Academy of Marketing Science,28(2), 226-238. doi:10.1177/0092070300282004

Spitznagel, E. (2020, January 25). Generation Z is bigger than millennials - and they're out to change the world. Retrieved from https://nypost.com/2020/01/25/generation-Z-isbigger-than-millennials-and-theyre-out-to-change-the-world/

Steigrad, A. (2018, February 26). NBC's Olympic ratings won't win any medals. Retrieved from https://nypost.com/2018/02/25/nbcs-olympic-ratings-wont-win-any-medals/

Stewart B., Smith, A., \& Nicholson, M. (2003). Sports Consumer Typologies: A Critical Review, Sports Marketing Quarterly, 12(4), 206-216.

Strashin, J. (2016, May 10). Why Canadian kids are dropping out of sports | CBC Sports. Retrieved from https://www.cbc.ca/sports/sports-participation-canada-kids-1.3573955

Sutton, W.A., McDonald, M.A., Milne, G.R., \& Cimperman, J. (1997). Creating and fostering fan identification in professional sports. Sport Marketing Quarterly, 6(1), $15-22$.

Tang, T., \& Cooper, R. (2018). The Most Social Games. Communication \& Sport,6(3), 308330. doi:10.1177/2167479516688438

The Telegraph. (2018, March 19). What is the future of sports consumption? Retrieved from https://www.telegraph.co.uk/business/events/business-of-sport/what-is-the-future-ofsports-consumption/

Tiago, M., \& Veríssimo, J. M. (2014). Digital marketing and social media: Why bother? Business Horizons, 57(6), 703-708. doi:10.1016/j.bushor.2014.07.002

Tomlinson, A. (2005). The commercialization of the Olympics: Cities, corporations, and the Olympic commodity. In K. Young, \& K. Wamsley (Eds.), The Global Olympics: Historical and Sociological Studies of the Modern Games London: JAI Press.

Tran, K. (2018, November 8). Why the esports audience is set to surge - and how brands can take advantage of increased fans and viewership. Retrieved from https://www.businessinsider.com/the-esports-audience-report-2018-11 
Truong, Y. (2009). An evaluation of the theory of planned behaviour in consumer acceptance of online video and television services. The Electronic Journal Information Systems Evaluation, 12(2), 197-206.

Varley, N. (2016). What truly makes an Olympics the greatest show on earth. Retrieved from https://www.telegraph.co.uk/men/the-filter/what-truly-makes-an-olympics-thegreatest-show-on-earth/

Vicario, M. D., Vivaldo, G., Bessi, A., Zollo, F., Scala, A., Caldarelli, G., \& Quattrociocchi, W. (2016). Echo Chambers: Emotional Contagion and Group Polarization on Facebook. Scientific Reports, 6(1). doi: 10.1038/srep37825

Williams, K. and Page, R. (2011). Marketing To The Generations, Journal of Behavioral Studies in Business, 3(1), 37-53.

Withiam, H. (2017, October 19). Inside the sports world's 'Generation Z' challenge. Retrieved from https://nypost.com/2017/10/19/inside-the-sports-worlds-generation-z-challenge/

Xiao, J. J., Tang, C., Serido, J., \& Shim, S. (2011). Antecedents and Consequences of Risky Credit Behavior among College Students: Application and Extension of the Theory of Planned Behavior. Journal of Public Policy \& Marketing, 30(2), 239-245. doi: 10.1509/jppm.30.2.239

Yuki, T. (2015). What Makes Brands Social Content Shareable on Facebook? Journal of Advertising Research, 55(4), 458-470. doi: 10.2501/jar-2015-026 